NBER WORKING PAPER SERIES

\title{
WHY HAVE COLLEGE COMPLETION RATES INCREASED? AN ANALYSIS OF RISING GRADES
}

\author{
Jeffrey T. Denning \\ Eric R. Eide \\ Kevin Mumford \\ Richard W. Patterson \\ Merrill Warnick \\ Working Paper 28710 \\ http://www.nber.org/papers/w28710
}

\author{
NATIONAL BUREAU OF ECONOMIC RESEARCH \\ 1050 Massachusetts Avenue \\ Cambridge, MA 02138 \\ April 2021
}

We thank Sandra Black, Lars Lefgren, Sarah Turner, and participants at the BYU R Squared seminar, NBER Education 2019 Spring Meetings, Society of Labor Economists 2019 Meetings, and Association for Education Finance and Policy 2019 Conference for useful comments on the draft. Research support was received from the College of Family, Home, and Social Sciences at Brigham Young University. We would like to thank Daniel Sabey and Michael Jensen for their excellent research assistance. The views expressed herein are those of the authors and do not necessarily reflect the views of the National Bureau of Economic Research.

NBER working papers are circulated for discussion and comment purposes. They have not been peer-reviewed or been subject to the review by the NBER Board of Directors that accompanies official NBER publications.

(C) 2021 by Jeffrey T. Denning, Eric R. Eide, Kevin Mumford, Richard W. Patterson, and Merrill Warnick. All rights reserved. Short sections of text, not to exceed two paragraphs, may be quoted without explicit permission provided that full credit, including $\odot$ notice, is given to the source. 
Why Have College Completion Rates Increased? An Analysis of Rising Grades

Jeffrey T. Denning, Eric R. Eide, Kevin Mumford, Richard W. Patterson, and Merrill Warnick

NBER Working Paper No. 28710

April 2021

JEL No. I20,I21,I23

\begin{abstract}
College completion rates declined from the 1970s to the 1990s. We document that this trend has reversed--since the 1990s, college completion rates have increased. We investigate the reasons for the increase in college graduation rates. Collectively, student characteristics, institutional resources, and institution attended do not explain much of the change. However, we show that grade inflation can explain much of the change in graduation rates. We show that GPA is a strong predictor of graduation rates and that GPAs have been rising since the 1990s. We also find that in national survey data and rich administrative data from 9 large public universities increases in college GPAs cannot be explained by student demographics, preparation, and school factors. Further, we find that at a public liberal arts college, grades have increased over time conditional on final exam performance.

\author{
Jeffrey T. Denning \\ Department of Economics \\ Brigham Young University \\ 2135 WVB \\ Provo, UT 84602 \\ and NBER \\ jeffdenning@byu.edu \\ Eric R. Eide \\ Department of Economics \\ Brigham Young University \\ 2120 WVB \\ Provo, UT 84602 \\ eide@byu.edu \\ Kevin Mumford \\ Department of Economics \\ Purdue University \\ 403 W State Street \\ West Lafayette, IN 47907 \\ mumford@purdue.edu
}

\author{
Richard W. Patterson \\ United States Military Academy \\ B107 Lincoln Hall \\ West Point, NY 10996 \\ richard.patterson@westpoint.edu \\ Merrill Warnick \\ Stanford University \\ merrill.warnick@gmail.com
}

A data appendix is available at http://www.nber.org/data-appendix/w28710 


\section{Introduction}

Students who attend college enjoy many long run benefits (Oreopoulos and Petronijevic, 2013). Students who complete college have even better outcomes (Jaeger and Page, 1996; Ost, Pan, and Webber, 2018). Despite the large returns to college completion, many students who enroll in college do not graduate, leading to what some have described as a "college completion crisis" (Deming, 2017). In fact, in 2016, the sixyear graduation rate for college completion at four-year schools was 67 percent (Shapiro et al., 2017). ${ }^{1}$ Consequently, policy and research attention has increasingly focused on college completion. ${ }^{2}$

In influential work, Bound, Lovenheim, and Turner (2010) (hereafter BLT) showed that changing institutional characteristics and, to a lesser extent, changing college preparedness, led to declining college completion rates from the 1970s to the 1990s. ${ }^{3}$ Our study asks what has happened to college completion rates after 1990. First, we document across three national data sources that aggregate trends have changedcollege completion rates increased from 1990 to present. The increase in graduation rates occurred across institution types including public and private universities as well as elite and non-elite institutions. College graduation rates increased for both men and women which is notable because men drove the decline documented in BLT.

Next, we investigate why college completion rates increased. We discuss relevant trends that could affect college graduation such as the college wage premium, enrollment, student preparation, study time, employment during college, price, state

\footnotetext{
${ }^{1}$ Hess and Hatalsky (2018) offer a nice summary of our understanding of the causes of college completion, policy tools, trends, etc.

${ }^{2}$ As examples see Scott-Clayton (2012), Castleman and Long (2016), Bettinger et al. (2019), Denning, Marx, Turner (2019), and Barr (2019).

3 The overall decline was largely due to the group of institutions that BLT refers to as public "non-top 50." Bound, Lovenheim, and Turner (2012) also document that time to degree has increased over a similar timeframe. Many subsequent papers explored the causal effect of institution attended on graduation (Cohodes and Goodman, 2014; Zimmerman, 2014; Goodman, Hurwitz, and Smith, 2017; Bleemer 2018; Black Denning Rothstein, 2020).
} 
support for higher education, and initial college attended. The trends in these variables almost uniformly would predict declining college graduation rates. We use two nationally representative surveys from the National Center for Education Statistics (NCES): National Education Longitudinal Study of 1988 (hereafter NELS:88 or sometimes referred to as 1988) and Education Longitudinal Study of 2002 (hereafter ELS:2002 or sometimes referred to 2002) to decompose the change in graduation rates into changes in student characteristics and institution-level factors (National Center for Education Statistics, 1988; 2002). ${ }^{4}$ These longitudinal student-level data sets have information on high school student background, academic preparation, college enrollment, and graduation outcomes. We find that student characteristics, institutional resources, and institution attended explain little of the change in graduation rates.

We then explore alternative hypotheses to explain the increase in graduation rates. We document that college student grade point averages are higher in ELS:2002 than in NELS:88. This is true after accounting for pre-collegiate math test scores, student demographics, high school coursework, and institution type attended. The increase in GPA happens across the distribution and explains a large share of the increase in college completion: changes in first-year GPA account for 95\% of the change in graduation rates in our decomposition.

Rising college grades and the subsequent increase in graduation rates could be caused by improved college preparation (not captured in NELS:88 and ELS:2002), increased learning in college, or grade inflation. To explore these provocative patterns in rising GPAs we observe in national data, we turn to administrative student data from two additional sources. First, in records obtained from the registrars of 9 Large Public Universities,${ }^{5}$ we document that rising grades persist when including controls for

\footnotetext{
${ }^{4}$ NELS:88 is the primary data set used for the later period in BLT.

${ }^{5}$ These data are obtained through the MIDFIELD partnership. The universities included are Clemson, Colorado, Colorado State, Florida, Florida State, Georgia Tech, North Carolina State, Purdue, and
} 
student demographics, home zip code, university attended, fixed effects for each SAT score, major choice, and first-semester courses taken. These results suggest that improving college preparation explains little of the increase in GPAs over time. Second, we use microdata from a Public Liberal Arts College that includes performance on course-level comprehensive final exams that appear to have a constant level of difficulty over time. We document that grades are not just increasing over time conditional on student characteristics and course schedules, but also conditional on final exam performance. Furthermore, in two required science courses that administered identical final exams across years, we find that grades are rising over time even when controlling for performance on identical final exams.

The results from the Large Public Universities and Public Liberal Arts College data suggest that rising grades cannot be explained by changes in student learning. Instead, our findings from the nationally-representative data, the sample of large public universities, and the public liberal arts college in combination with trends in student time spent studying and labor force participation in college suggest that GPAs have been rising due to relaxed standards. These relaxed standards account for much of the increase in college graduation rates.

The rest of the paper proceeds as follows. Section 2 describes trends in college graduation rate and other related trends. Section 3 outlines potential explanations for the change in college graduation rates. Section 4 describes the data. Section 5 discusses the empirical strategy. Section 6 contains the results and Section 7 concludes.

\section{Trends in College Graduation Rates}

Virginia Tech. Institutions that participate in the MIDFIELD partnership share de-identified longitudinal student record data for all degree-seeking undergraduate students. 
We begin by establishing that college graduation rates have increased since the 1990s.

We use three data sources to document these trends. All three sources have limitations; however, the evidence is consistent across all sources we consider. ${ }^{6}$

First, we use the decennial census to examine college graduation trends following BLT (Ruggles et al., 2019). Figure 1 shows the ratio of bachelor's recipients to those with some college among respondents who are 25 years old. If the college graduation rate increases, this ratio will increase. The decline from 1970 to 1990 is visible and is the focus of BLT. However, from 1990 to 2010, the ratio of BA recipients to those with some college increased - especially for women. ${ }^{7}$

In the period that BLT studies, there were no nationwide institution-level graduation data available. However, NCES started publishing cohort graduation rates by college starting with the entering class of 1991 . We summarize the trends in these graduation rates in Figure 2. ${ }^{8}$ Integrated Postsecondary Education Data System (IPEDS) collects graduation rates for all schools who receive Title IV federal financial aid. However, the graduation rates are calculated only for first-time, full-time students who begin in the fall. ${ }^{9}$ We focus on the six-year graduation rate in Figure 2. Despite this limitation, the trends in the IPEDs data mirror the ratio of the number of bachelor's degrees to people with some college found in Figure 1. Long (2018) notes similar trends

\footnotetext{
${ }^{6}$ We also find similar graduation patterns in our Large Public Universities and Public Liberal Arts college administrative data sources. Table A1 shows that six-year graduation rates in our Large Public Universities sample increased from 62\% to 64\% between 1990 and 2000 and Table A2 shows that six-year graduation rates at our Public Liberal Arts college increased from 83\% to 86\% between 2001-2013 and 2010-2012 entering cohorts.

${ }^{7}$ Archidald, Feldman, and McHenry (2015) document this fact using similar census data.

${ }^{8}$ For Figure 2, we exclude schools that were predominantly online because online schools are different in many ways. Online schools are concentrated at for-profit institutions and have lower graduation rates than traditional schools. Information on online enrollment is first available in 2012 in IPEDS. We follow the convention of Deming et al. (2015) and label institutions that were predominantly online in 2012 as online prior to 2012.

9 These graduation rates will not capture students who do not fit this description. For instance, this measure is likely to do a poor job measuring college completion at for-profit colleges where many students are "nontraditional."
} 
in graduation rates using the same data starting in the entering class of 1998 and describes differences in graduation rates across institution type, student demographics, and the consequences of non-completion. ${ }^{10}$

Throughout this paper, we consider enrollment and graduation separately by institution type. We follow the convention of BLT with one notable difference--we separately consider for-profit institutions. ${ }^{11}$ With that modification, we categorize schools as follows: top 50 public, non-top 50 public, highly selective non-profit (private non-profit + public), non-selective non-profit, and for-profit. We follow BLT in our definition of Top 50 and Selective for public schools and private schools respectively and provide complete descriptions of these groups in Section 4.

Figure 2 shows there is substantial heterogeneity in the graduation rates across institution types. The graduation rates are highest for highly selective non-profit universities and top 50 publics. The lowest graduation rates are for for-profit institutions. Setting aside for-profit schools, graduation rates continuously increase from 1991-2010. Not all school types had increases of the same size; public schools had larger increases than non-profit private schools at similar levels of selectivity. However, the direction of the graduation rates is consistent across institution types. When combining all schools weighted by enrollment (the black dashed line), the graduation rate increases from 52.0 percent to 59.7 percent. For-profit schools exhibit a different pattern. Graduation rates decline for the 20 years we observe which coincides with the growth in the for-profit sector as seen in Figure A1. The growth in the for-profit sector suggests some of the decline may be due to changing composition of the sector's institutions or students.

\footnotetext{
${ }^{10}$ Our contribution relative to Long (2018) is that we document the graduation rate increase over a longer time frame, across more sources and, most importantly, we investigate the reasons for this increase.

${ }^{11}$ For-profit institutions have lower graduation rates and increased enrollments in the 2000s. Further, forprofits are different in many ways from nonprofit institutions (Deming et al. 2012).
} 
We also show that the graduation rates for the two nationally representative samples followed a similar pattern. We define college graduation as graduation within 8 years of expected high school graduation following BLT. ${ }^{12}$ In Table 1, we show the eight-year graduation rate for the two nationally representative surveys used in this paper, National Education Longitudinal Study of 1988 (NELS:88) and the Education Longitudinal Study of 2002 (ELS: 2002). We show that the overall graduation rate increased by 3.77 percentage points. We find statistically significant increases in graduation rates for top 50 and non-top 50 (at the ten percent level) public schools of 8.57 and 4.89 percentage points respectively. We also see statistically significant increases at community colleges and all non-profit colleges. Less selective and highly selective private universities do not have a statistically significant change in their graduation rates across NELS:88 and ELS:2002. This contrasts with aggregate graduation trends in IPEDS but may be due to relatively small samples in the individual-level surveys.

We verify that the changes in graduation rates in NELS:88 and ELS:2002 are similar to those observed in IPEDS. NELS:88 and ELS:2002 represent the high school graduating cohorts of 1992 and 2004, respectively. The change in overall graduation rates for the entering cohorts of 1992 to 2004 in IPEDS is 5.74 percentage points which is similar but somewhat larger to what is observed across NELS:88 and ELS:2002 at 3.77. Hence, using NELS:88 and ELS:2002 should yield insight because the change in graduation rates is similar to observed aggregate changes.

\section{Potential Explanations for Changes in Graduation Rate}

\footnotetext{
12 We know when students actually graduate from high school but we use years from expected high school graduation to avoid conditioning our outcome on an endogenous variable (actual high school graduation).
} 
We initially consider two types of explanations for changes in college graduation rates: student-level characteristics and institution-level characteristics. Student characteristics that may affect college graduation include student preparation, choice of college major, work during school, and time spent studying. Institution characteristics that may explain changes in graduation rates include the quality of instruction, financial aid, student services, and standards for degree receipt. Some of these explanations we will later explore directly (e.g. student preparation, major choice, and standards for degree receipt) while others we consider given the existing evidence (e.g. time spent studying, employment during school, and returns to education). In the end, we conclude that standards for degree receipt are most likely to explain increasing graduation rates.

\section{Student-Driven Explanations}

In trying to explain the increases in college completion, several trends are worth noting. One possibility is that changes in student composition could explain changes in college graduation rates. Table 2 shows that college enrollment rose from 69.3 percent in NELS:88 to 78.3 percent in ELS:2002. ${ }^{13}$ Additionally, Figure A1 shows that college enrollment has grown steadily since 1975 and that, at least since the 1990s, enrollment has increased at every type of institution. With a larger fraction of students entering college, there may be more entrants who are relatively less prepared because as more students enter college, they likely come from farther down the distribution of student achievement. Therefore, enrollment sector trends are unlikely to explain increases in graduation rates.

Another possibility is that potential college students are more prepared for college than in the past. Measuring changes in preparation for marginal college entrants

\footnotetext{
13 The equivalent fraction of high school completers enrolling in college in Figure A1 Panel A are 61.9 and 66.7. These two data sources disagree slightly on the level of college enrollment but present very similar trends in college enrollment over the same years.
} 
could be confounded with the increase in college attendance if the increase in college attendance coincided with an increase in performance. Instead, we note that performance of 17-year-old students on the math and reading portions of National Assessment of Educational Progress (NAEP) is essentially unchanged since the 1970s (National Center for Education Statistics, 2013). ${ }^{14}$ Hence as college enrollment increases, the average preparation for college entrants would fall because the distribution of student ability is constant. We expect college preparation would decrease in the time period studied given that college enrollment has increased and that performance on the NAEP is unchanged. ${ }^{15}$ Trends in enrollment and student preparation would predict reduced college completion. ${ }^{16}$

Once students arrive at college, changing major choices could affect college completion. To explore the role of major choice, we explore what graduation rates would be if we changed the distribution of majors while holding fixed the graduation rates of any particular major. We find that students have not moved towards higher graduation rate majors over time (details provided in Section 6.2).

\footnotetext{
${ }^{14}$ Blagg and Chingos (2016) explore the reason for the stagnating NAEP scores and conclude that "stagnant achievement among high school students is a real phenomenon." They discuss potential explanations for this phenomenon including changes in high school persistence, test/subject alignment, and students taking the test less seriously and conclude that none of these explanations are likely to explain the change. Notably, the Program for International Student Assessment (PISA) also shows no evidence of achievement gains for 15 year-olds in the United States.

${ }_{15}$ Archibald, Feldman, and McHenry (2015) consider the change in preparation among college enrollees. They document a decline in preparation as measured by math test scores and reading test scores. They find that student high school GPA matters for college enrollment. However, the increase in high school GPAs is difficult to interpret because GPAs are growing faster in affluent schools than in less affluent schools (Gershenson, 2018). They argue that students matched to schools on the basis of high school GPA reduce the impact of lower average math scores.

${ }^{16}$ We assign students their math percentile in the distribution of math test scores. We argue this represents students' absolute level of preparation because the overall distribution of student preparation is unchanged as discussed. In Table 3, college entrants' math percentile decreases from the 59th percentile to the 56th percentile. The decline in math percentile is also present among college graduates where it fell from the 71st percentile to the 68th percentile.
} 
Changes in learning could also affect graduation rates. However, students are spending less time studying and more time employed over the time period we consider. Babcock and Marks (2011) show a drop in the number of hours studied from 1961 to 2003. Neither student demographics including race, gender, and parent education nor student SAT scores can explain much of the change in college study habits.

Concurrently, college students increased their labor supply over this period. ScottClayton (2012) shows that average hours worked doubled from 1970 to 2000. However, student labor supply fell during the Great Recession. All else equal, we would expect declining graduation rates when students spend more time working for wages during college due to decreased study time, less full-time enrollment, etc. Trends in student labor supply and study time would predict declining college graduation rates, except perhaps during the Great Recession.

Finally, BLT notes that an increasing college wage premium would predict an increasing graduation rate. However, the college wage premium has flattened beginning for cohorts born around 1970 (Ashworth and Ransom, 2019). ${ }^{17}$ A stable college wage premium for young workers contrasts with earlier periods (including the period studied in BLT) where the college wage premium was growing. Hence, in the period we study the college wage premium is unlikely to explain increasing graduation rates.

\section{Institutional explanations}

The types of institutions students attend could potentially explain graduation rate patterns. Table 2 shows the changes in initial college attended across the NELS:88 and ELS:2002 cohorts. The share of students attending non-top 50 public and for-profit

\footnotetext{
${ }_{17}$ Valletta (2016) shows a similar trend starting slightly later with the wage premium flattening starting in 2000. Valletta (2016) considers workers age 25-64 whereas Ashworth and Ransom (2019) consider workers age 25-34 which may explain some of the discrepancy.
} 
colleges increased. The share of students attending highly selective private, less selective private, top 50 public and community colleges decreased. The pattern of enrollment increases in non-top 50 public colleges balanced against the decrease in community college attendance and increased for-profit attendance leads to an ambiguous prediction about the overall college completion rate if the average graduation rate of an institution causally affects college graduation. ${ }^{18}$

It is unlikely that changes in college affordability could explain changes in graduation rates. College has become more expensive since the 1990s. Inflation adjusted published tuition and fees have increased by over 300 percent since 1987. The net price of college accounting for financial aid has nearly doubled since 1997 for public four-year institutions (CollegeBoard, 2017). The price of college has been shown to affect college completion (Scott-Clayton, 2011; Castleman and Long, 2016; Bettinger et al., 2019; Denning, 2019). Relatedly, state support for higher education per student has declined since 1985 (CollegeBoard, 2017), and state funding for higher education has been shown to affect enrollment and graduation rates (Deming and Walters, 2017) $\cdot{ }^{19}$ Overall, the rising price of college would predict declining graduation.

Another possibility is that the instructional resources, such as student-to-faculty ratios, have changed. Instructional resources could affect graduation rates through changes in education quality or the availability of required courses. A change in instructional resources is a potentially promising explanation, as BLT found changing student-to-faculty ratios explained approximately $75 \%$ of declining graduation rates at public institutions in earlier cohorts. However, in Table A3, we find that between the

\footnotetext{
${ }^{18}$ This assumption has good empirical support (Cohodes and Goodman, 2014; Zimmerman, 2014; Goodman, Hurwitz, and Smith, 2017).

${ }^{19}$ Bailey and Dynarski (2011) document that there have been increases in the income gap in unconditional college graduation. That is, graduation without conditioning on college attendance. In contrast, we focus on graduation rates among those who enter college and document these are increasing. Increasing unconditional graduation rates could happen with declining graduation rates or increasing graduation rates.
} 
NELS:88 and ELS:2002 samples student-faculty ratios increased from 39.4 to 40.4 and instructional expenditures fell from $\$ 4,581$ to $\$ 4,288 .{ }^{20}$ As we explain in detail in Section 6 , both changes in instructional resources predict a decrease in graduation rates.

Finally, there has been increased policy attention on college completion during this period. For example, the number of state policies that tie appropriations for higher education to college completion via performance funding mechanisms has increased. The use of these mechanisms grew beginning in the 1990s. Evidence on the effect of these mechanisms is mixed, with some studies finding that they affect degree production (Hillman, Tandberg, \& Fryer, 2015; Tandberg \& Hillman, 2014; Hillman, Fryar, \& Crespín-Trujillo, 2017) and some finding that they do not (Hillman, Tandberg, \& Gross, 2014). Increased attention to graduation and performance-based-funding gives schools an incentive to increase graduation rates. However, even if performance funding does affect graduation, it would be an indirect mechanism. For performance funding to have an effect, it must induce schools to change something about the degree production process.

\section{Changing standards for degree completion}

Trends in the college wage premium, student enrollment, student preparation, student studying, labor supply in college, time spent studying, and the price of college would all predict decreasing college graduation rates. The patterns for enrollment by institution type yields an ambiguous prediction. Despite the bulk of the trends predicting decreasing graduation, we document that the college graduation rate is increasing. These trends foreshadow what we find in our analysis and present a puzzle. The trends in the variables that explained the decline documented in BLT will not be able to explain the increase in graduation rates observed from 1990 to 2010.

\footnotetext{
${ }^{20}$ We use the Higher Education Price Index to deflate spending.
} 
We propose, and test for, an additional channel that may change college completion rates-standards for degree receipt. Instructors, departments, and institutions may have incentives to inflate grades or increase GPAs for reasons other than student performance. Instructors who give students higher grades receive better teaching evaluations (Krautmann and Sander, 1999; Langbein, 2008). Departments that increase grades see higher student enrollments (Butcher, McEwan, Weerapana, 2014). Additionally, colleges have strategic incentives to offer less informative grades (Boleslavsky and Cotton, 2015) and institutional efforts to curb grade inflation can fail to make transcripts more informative and can instead reduce welfare (Bar, Kadiyali, Zussman, 2012). ${ }^{21}$

Increasing grades explain, in a statistical sense, a majority of the changes in graduation rates in our decomposition exercise. To interpret whether the increase in grades is due to changes in performance or grade inflation, we supplement our analysis with results from two additional samples. We first document similar trends in graduation and GPA in our Large Public Universities and Public Liberal Arts College samples. We then show that grades are increasing while controlling very finely for student preparation in the Large Public Universities sample. We also show that grades are increasing in Public Liberal Arts College after controlling for student learning. These two additional samples present evidence that the increase in grades is consistent with grade inflation.

\footnotetext{
${ }^{21}$ Evidence on patterns in "grade-inflation" is mixed with some studies finding support for grade inflation (Rojstaczer and Healy, 2012) and others finding none (Pattison, Grodsky, and Muller, 2013). We will discuss grade inflation in Section 6. Griffith and Sovero (2019) use administrative data from a public research university and find that grades have increased significantly since 1980 . They hypothesize that an increasing number of instructors with job uncertainty may face pressures to increase grades, which is borne out empirically. Bar et al. (2009) show that at Cornell University, publishing average course grades induced students to enroll in classes with historically higher grades.
} 


\section{Data}

We use microdata to examine the reasons for the increase in college graduation rates. We begin with two longitudinal surveys sponsored by the National Center for Education Statistics: the National Education Longitudinal Study of 1988 (NELS:88) and the Education Longitudinal Study of 2002 (ELS:2002). The NELS:88 and ELS:2002 capture college-going behavior of the high school classes of 1992 and 2004, respectively. The surveys provide information on whether a student attended college, the type of college attended, whether the student graduated from college, and the timing of college attendance and graduation.

The NELS:88 is a nationally representative, longitudinal study of $8^{\text {th }}$ graders in the U.S. in 1988. The cohort was again surveyed in four follow-ups which occurred in 1990, 1992, 1994, and 2000. Postsecondary transcripts were also collected in 2000. The ELS:2002 is a nationally representative, longitudinal study of $10^{\text {th }}$ graders in 2002 . There were three follow-up surveys that were administered in 2004, 2006, and 2012, with postsecondary transcripts collected in 2013. Importantly, both surveys include student assessments in math (and other areas) taken during high school, and we use the math assessments as a measure of student preparedness for college. Another strength of these surveys is they contain a host of individual and family background variables. We use father's and mother's educational attainment (no high school diploma, high school diploma, some college, BA, graduate school), parental income (divided into income level categories), gender (male), and race/ethnicity (Asian, Hispanic, African American, White). Following BLT, we impute pre-collegiate math test scores, mother's education and father's education for both surveys because these data are missing for many 
students. We also impute first-year college GPA for both surveys. For NELS:88, we also impute parental income. ${ }^{22}$

We follow BLT in how we define college attendance and college completion. We consider students who attend college within two years of when their high school cohort would be expected to graduate. The college completion rate is the proportion of students who attend college within two years of when the high school cohort would be expected to graduate and obtain a BA within eight years of expected high school graduation.

We also follow BLT in assigning institutions to types which is primarily based on the 2005 U.S. News and World Report college rankings. ${ }^{23}$ We assign the highest rated 50 public schools to the top-50 public category. The 65 highest rated private universities, the 50 highest rated liberal arts colleges, and the armed service academies are categorized as highly selective private category. ${ }^{24}$ Other 4-year public schools are assigned to the non-top 50 public category, and other 4-year not-for-profit private schools were assigned to the less selective private category. Not-for-profit 2-year colleges are assigned to the community college category. Due to the recent rise in forprofit colleges, we created a new category, for-profit colleges, and placed all for-profit colleges in this category.

Table 3 presents summary statistics for our two samples. From NELS:88 to ELS:2002 college enrollees had lower pre-collegiate math percentiles, moving from 58.88 to 55.93. Despite this decline in preparation, first-year college GPA increased from 2.44

\footnotetext{
${ }^{22}$ We follow BLT's imputation strategy by using multiple imputation by chained equation (MICE) algorithm, implemented by the STATA module "ICE." See the data appendix for more information on imputation.

${ }^{23}$ We deviate from BLT's assignment due to a few cases, which are described in the appendix. We opted for using the same rankings to aid in comparability and because rankings are quite stable across years. ${ }^{24}$ We follow BLT in classifying armed services academies as private rather than public institutions. While they are publicly funded, in many ways, e.g. academic ability of students, they are more similar to highly selective private institutions.
} 
to 2.65. Student-faculty ratios increased slightly from 39.35 to 40.43 . Parental education increased from NELS:88 to ELS:2002, where students whose mother had at least a bachelor's degree increased by 5 percentage points. Underrepresented minorities constituted a bit larger fraction of college enrollment in ELS:2002 than in NELS:88. Parental income shifted towards middle incomes. Lastly, the fraction of college students that are male declined from 49 percent to 46 percent.

To explain the role of rising GPAs in increasing graduation rates, we incorporate individual-by-course level administrative data from two sources. The first dataset combines microdata for all degree-seeking undergraduate students at 9 Large Public Universities (Clemson, Colorado, Colorado State, Florida, Florida State, Georgia Tech, North Carolina State, Purdue, and Virginia Tech) for cohorts entering between 1990 and 2000 (Ohland and Long, 2020). The Large Public Universities data includes student demographic information, admissions information including SAT scores, individual course grades, and degrees earned for the 530,036 students entering one of these institutions between 1990 and 2000. ${ }^{25}$ Table A1 presents summary statistics for the 1990 entering cohort as well as the 2000 entering cohort and shows that these students are quite similar to those from the nationally-representative NELS:88 and ELS:2002 in terms of math quartile, race, and gender. ${ }^{26}$ The first-year GPA for all students increases from 2.68 to 2.79 over the decade.

Second, we analyze trends in GPA using detailed student course performance microdata from a Public Liberal Arts College (Denning et al., 2021). These data include student demographic information, graduation rates, individual course grades, and student scores on final exams for 14,193 students entering the institution between 2001

\footnotetext{
${ }^{25}$ The MIDFIELD partnership under which we obtained the data does not allow us to report any results separately by institution that would enable readers to identify the institution. Students without a reported SAT or ACT test score (primarily transfer students) are excluded from the tables.

${ }^{26}$ The math test frames are different but tell a similar story of positive selection on the basis of math tests into college.
} 
and 2012. Table A2 presents summary statistics for early (2001-2003) and late (20102012) entering cohorts. While the population at the Public Liberal Arts College is unique in some ways, its distribution across race and ethnicity is similar to those in the NELS:88 and ELS:2002. Further, when comparing Public Liberal Arts College dynamics to changes between NELS:88 and ELS:2002, there are similar trends in GPA growth (2.77 to 3.02) and graduation rates (83.1 percent to 85.9 percent) across early and late cohorts.

While these additional administrative datasets are not nationally representative, they offer larger samples with the course grades of every undergraduate student and more detailed pre-college student ability measures from the college application. In the case of the Public Liberal Arts College, course-level final exam data separate from the letter grade provides an additional advantage.

\section{Empirical Strategy for Graduation Rate Decomposition}

We wish to decompose the increase in college graduation rates into student factors and institutional factors. In doing this, we closely follow the method used by BLT which is a modified Blinder-Oaxaca decomposition (Blinder 1973; Oaxaca 1973). The key challenge arises because we are interested in college graduation, which is discrete. Throughout this section both institutional and student factors will be referred to as $x_{j}$.

First, we use a logit model to predict college completion in both the NELS:88 and ELS:2002 samples. This allows for nonlinear effects of any $x_{j}$ which are likely to be important in describing changes in graduation rates. If we were using a linear framework, we could simply take the mean change in observable characteristics $\left(x_{j}\right)$ across the two periods and multiply it by the estimated effect of the observable characteristic. However, using a logit does not allow this simple decomposition because the effect of changes in a given observable characteristic not only depends on the mean 
size of the change, but also where in the distribution of the characteristic that change occurs. To simulate the overall change in graduation rates, we use the estimates from the ELS:2002 and the covariates in the NELS:88 to generate a predicted probability of graduation and compare this to the actual graduation rates in ELS:2002. Generating how much of the overall change is due to changes in all characteristics simply compares the predicted graduation rates using NELS:88 covariates combined with the estimated coefficients from the ELS:2002 to the actual graduation rates in the ELS:2002.

We also wish to examine the effect of a particular $x_{j}$, which is not as straightforward. In principle, we would like to generate the distribution of a particular $x_{j}$ from the ELS:2002 sample (i.e. the later cohort) in the NELS:88 sample (i.e. the early cohort) while holding all other variables constant. We follow BLT and do this by matching observations across samples. We will use an example to illustrate this pointmath test score percentile. For all students in NELS:88 we assign each student a rank in the distribution of pre-collegiate math test scores; we also do this for all students in ELS:2002. We then match each student in the ELS:2002 with the student who has the same rank in the NELS:88 and assign the test score percentile from the NELS:88. We break ties randomly. This process ensures that we do not assign students with high math scores with students who we would expect to have low math scores. ${ }^{27}$ After matching, we then apply the estimates from the ELS:2002 model and see how predicted graduation probabilities change. ${ }^{28}$

To interpret these changes causally, we must assume that the logit model of graduation on $x_{j}$ accurately captures the causal effect and the relationship between the

\footnotetext{
${ }^{27}$ We also reweight the ELS:2002 and NELS:88 samples to have the same number of observations to facilitate matching. For initial college enrolled there is not a natural ranking of school types and so we use propensity score matching to predict which college a student would attend. Following BLT, we used propensity score matching implemented with the STATA module "psmatch2."

${ }^{28}$ Alternatively, we could use the estimates from NELS:88 and distribution of the covariates from ELS:2002. These results are very similar to those presented in the paper.
} 
$x_{j}$ and graduation is the same in both time periods. This is a strong assumption that may not hold. However, even if this strong assumption does not hold, this framework developed in BLT offers a consistent way to decompose the changes in the graduation rate into the changes in $x_{j}$.

The coefficients from the logit for the whole sample and by school type are presented in Table A4 with ELS:2002 in Panel A and NELS:88 presented in Panel B. We do not discuss these in detail but do note that the coefficients have the expected sign. In particular, a higher student-faculty ratio, lower income, being male, and lower parental educational attainment are associated with reduced probability of graduation.

\section{Results}

We first start with our base specification which includes measures of student preparedness, the log of the student-faculty ratio and initial school type in Table 4 . This is the same specification used in BLT for comparability. It decomposes the change in graduation rates into two main groups. First, we consider changes due to student characteristics (demand side) which include pre-collegiate math percentile and other student characteristics such as parent education, income, and race. Second, we present changes due to institution-level factors (supply side) which includes student-faculty ratios and initial school types.

Focusing on the full sample, there is a 3.77 percentage point increase in the probability of graduation from the NELS:88 cohort to the ELS:2002 cohort. The total explained by observable characteristics is -1.92 . This suggests that covariates would predict that graduation rates would decrease by 1.92 percentage points. Hence, the residual or unexplained change is 5.69 percentage points or 151 percent of the change is unexplained by covariates. Student preparedness would predict a decline in graduation 
rates of 1.26 percentage points. Student-faculty ratios explain a 0.28 percentage point decline and initial school type explains no change in graduation rates.

Based on the full sample, Table 4 shows that the distribution of student characteristics and supply side factors cannot explain much of the increase in graduation rate-in fact, they predict graduation declines. This finding was previewed in Section 3 where many of the trends that may affect graduation went in the wrong direction to explain completion rate trends. Hence, we spend the rest of the paper exploring explanations not considered in BLT.

One potential reason that previous explanations no longer explain the change in graduation rates is that the covariates are no longer predictive of graduation. However, Table A4 reports the coefficients for various covariates. All have the expected sign and are statistically significant. Further, the coefficients are qualitatively similar across the samples.

\subsection{Rising College Grades}

In Section 3 we previewed a potential change that could explain increasing graduation rates despite the apparent changes in student preparation and other covariates-rising college grades. Both improving preparation for college (in ways not captured in NELS:88 and ELS:2002) or relaxing grading standards would increase graduation rates and be evidenced by increases in GPAs.

We find evidence that the increase in grades is due to grade inflation. We document several facts about GPA in the NELS:88, ELS:2002, Large Public Universities, and Public Liberal Arts datasets. First, GPA predicts graduation. Second, GPAs are increasing over the time frame considered. Third, the growth in GPAs is not well explained by student observable characteristics, course taking behavior, or performance on final exams that have a constant level of difficulty over time. These facts combined 
with trends in student study time and employment suggest that standards for degree receipt have changed due to grade inflation.

\section{GPA predicts graduation}

First-year college GPA is predictive of graduation in each of our datasets. Table 5 presents the coefficients from a linear probability model where graduation is predicted using a linear effect of GPA. Panel A presents results based on the NELS:88 and ELS:2002 samples, and Panel B the Public Liberal Arts College. The relationship between GPA and graduation rate between the NCES samples in Panel A is very similar so we focus on NELS:88 in our discussion. Without controlling for any other covariates, a one point increase in GPA is associated with a 30 percentage point increase in the probability of graduation. Subsequently controlling for student characteristics, graduation rate of a student's selected major, and major fixed effects still yields large and precisely estimated associations between GPA and graduation; in each case a one point increase in GPA and leads to a 23-24 percentage point increase in graduation (standard errors are approximately 1 percentage point). Similarly, in Table A5 and Panel B of Table 5, we find that a one point increase in GPA corresponds to 16-21 percentage point increase in graduation in the Large Public Universities and Public Liberal Arts samples depending on the dataset and controls included.

We also show that this relationship is somewhat nonlinear in each dataset. In both Figures 3 (NELS:88 and ELS:2002) and Figure A2 (Large Public Universities and Public Liberal Arts) we regress graduation on bins of GPA while controlling for covariates such as demographics, test scores, and institution type and plot the coefficients and $95 \%$ confidence intervals with GPAs larger than 3.5 being the excluded category. In each sample and in each cohort the change in the probability of graduation is largest for GPAs between 1.0 and 2.5. That is, improvements in GPAs in that range 
correlate with meaningful increases in graduation whereas GPAs above or below that range do not change the probability of graduation as much.

GPA likely has a causal effect on graduation for two reasons. First, students generally must maintain a GPA above certain thresholds to avoid dismissal. ${ }^{29}$ This induces a mechanical, causal relationship between GPA and graduation (Ost, Pan, Webber 2018). Second, GPA can also act as a signal about a student's schooling ability (Arcidiacono et al., 2016; Butcher, McEwan, Weerapana, 2014). In either of these cases, higher GPAs cause more students to graduate.

\section{GPAs are increasing over time}

Table 3 showed that GPAs among enrollees increased from 2.44 to 2.65 between the NELS:88 and ELS:2002 samples. We explore changes in GPA in more detail-where did GPAs increase the most? Figure 4, which plots the cumulative density function of GPAs for each type of institution, shows that GPAs increased throughout the distribution for every type of school we examine except for-profit schools. The GPA increases were somewhat larger at public schools than at private schools, perhaps because the GPAs at private schools were already much higher than at public schools on average in NELS:88. Overall, we find that 11 percent more students have a GPA above a 2.0 in ELS:2002 than in NELS:88 (Table A7). This point is notable because many institutions have rules about academic probation requiring GPAs of around 2.0 to continue enrollment. ${ }^{30}$ Hence, the changes in GPA occurred where GPA is most predictive of changes in graduation.

\footnotetext{
${ }^{29}$ For example, each institution in our Large Public Universities Sample has a dismissal policy based on cumulative GPA. These dismissal policies have varying details, but typically require students to maintain a 2.0 GPA.

${ }^{30}$ This can also be true for Satisfactory Academic Progress which is required to maintain financial aid eligibility (Schudde and Scott-Clayton, 2016).
} 
This pattern of increasing GPAs is present in every sample we observe. Figure A3 examines GPAs in two samples of Large Public Universities and shows that GPAs increased between 1990 and 2000 and again between 2009 and 2014. ${ }^{31}$ Figure A4 shows a large increase in GPAs between the 2001-2003 and 2010-2012 cohorts at the Public Liberal Arts College and, similar to patterns shown in Figures 4 and A3, the fraction of students with at least a 2.0 GPA significantly increased.

Higher GPAs are not explained by changes in student characteristics or preparation

GPAs are increasing over time and cannot be fully explained by changes in student characteristics. We test this in the NELS:88 and ELS:2002 samples by regressing GPA on pre-collegiate math score, demographic characteristics, initial school type, and an indicator for being in the later period (being in ELS:2002) in Table 6. If student characteristics changed in ways that predicted the change in GPA, the ELS:2002 indicator would become smaller with the additional controls. However, additional controls including parent education, parent income, race, gender, and math test scores do not change the effect of GPA substantively and there is a meaningful and statistically significant coefficient on ELS:2002 ranging from 0.21 to 0.31 indicating that GPA is higher in ELS:2002.

We also control for student preparedness using the rich data on high school course taking in the NCES data sets. We create a set of indicator variables for advanced coursework that is consistently measured. These include courses in calculus, physics, chemistry, biology, and US history. We control for these in column 5. We also control

\footnotetext{
31 The lower panel of Figure A3 shows the distribution of first-year GPA in 2009 and 2014 for a different sample of public schools where we observe course grades in more recent years including Colorado, Colorado State, North Carolina State, North Carolina - Charlotte, Oklahoma, Purdue, South Dakota School of Mines, and Utah State. First-year GPA continues to increase in the later period, though it is running out of expansion room in the top right-hand corner of the figure suggesting that the increase in the distribution of GPAs at these institutions will necessarily slow.
} 
for some courses which did not appear in the earlier period in column 6 (namely AP Language and Literature courses). Finally, we control for the total number of math and science courses taken in high school in column 7. In every case, our main result holds: student preparedness measured through test scores and high school course work does not explain the increase in college first-year GPA.

While the patterns observed in the NELS:88 and ELS:2002 nationally representative data indicate that rising GPAs may be due to decreasing standards, administrative data from our Large Public Universities allow us to explore the source of rising GPAs in more detail. An advantage of this data is that it includes additional information about potential student preparation including home zip code, transfer status, and U.S. citizenship. Furthermore, the size of the data allows us to flexibly control for SAT scores with fixed effects for every SAT math and reading score interacted with the university. ${ }^{32}$ Table 7 is a cross-cohort analysis where we examine the time trend in first-year GPA. Column 1 shows a statistically significant increase of 0.019 per year in first-year GPA between 1990 and 2000. Controlling for demographic characteristics, school attended, and home zip code leave the coefficient unchanged. Including very flexible controls for SAT scores reduces the coefficient on year of entry only slightly to 0.014 . We also include fixed effects for major by institution to account for the potential of changing major composition. Last, we include fixed effects for all first-semester courses and the coefficient is unchanged. We include these fixed effects to account for shifts in student course taking that may explain changes in GPA but find that courses taken cannot explain the change in GPA.

\footnotetext{
32 We restrict our sample to students who have a valid measurement for all of the characteristics. This largely omits transfer students who often do not have an SAT score. The SAT was recentered beginning in 1995 and so we use a concordance to make scores comparable before and after this date. Similarly, we use published concordances to convert ACT scores to SAT equivalents.
} 
This evidence shows that rising grades cannot be meaningfully explained by demographics, preparation, courses, major, or school type. Put another way, equally prepared students in later cohorts from the same zip code, of the same gender and race, with the same initial courses, the same major, and at the same institution have higher first-year GPAs than earlier cohorts.

Interpreting these facts about GPA

We have documented that GPAs are higher at the end of our study period than they were at the beginning and that the increase is not explained by observable student characteristics. We interpret this evidence as consistent with grade inflation. However, other explanations are consistent with higher GPAs. For instance, students could be studying more. Unfortunately, we do not observe student study time or effort in our data. However, the trends presented in Babcock and Marks (2011) suggest that time spent studying declined over this period. Another explanation is that perhaps students are more efficient at studying. This could be true but is hard to test absent measures of student study. The gains from efficiency would have to be large enough to exceed the decline in study time.

The ideal test for whether rising grades can be explained by student preparation/effort/learning would be a comprehensive assessment that had constant difficulty over years given to students that assessed learning occurring in all college courses. Then, we could see if the grades of students who scored the same on the assessment were increasing over time. We closely approximate this ideal test with our Public Liberal Arts College data. These data allow us to control for course-level final exam scores, which provide potentially objective measures of student knowledge and learning. Specifically, all freshmen must complete a required liberal arts curriculum that has common final exams in each course-exams that do not appear to have increased in 
difficulty over time. ${ }^{33}$ Furthermore, these final exams are often graded automatically or in teams and, in at least one subject, students are given identical exams year-after-year. ${ }^{34}$

In Table 8, we estimate how GPA has changed over time at the individual by course level at Public Liberal Arts College, successively adding controls for each course, demographic characteristics, final exam scores, and, in two required science courses, the exact version of test given. In Column 1 we estimate the correlation between the year of entry and freshman course grades. We find that a year later entry corresponds to a statistically significant 0.025 point increase in GPA. In columns 2, 3, and 4 we successively control for course fixed effects, student characteristics including SAT test score quartiles, and final exam scores. We find that including these controls has little effect on the relationship between year of entry and freshman grades, suggesting that broad changes in the courses students take, characteristics of students, and overall learning (as measured by final exam performance) are unlikely to explain improving GPAs over time. To investigate whether student sorting into courses to which they are better matched could explain these patterns, in column 5 we restrict our analysis to courses that are part of a required liberal arts curriculum. Our results suggest that student sorting is unlikely to explain improving GPAs over time, as our estimates are indistinguishable from those in column 4.

One potential weakness of this approach is that courses may change or final exam content could change over time. While course representatives do not think this is

\footnotetext{
${ }^{33}$ We asked course representatives in an email survey the following free response question: "From 2001 (or as early as you are aware) to now, has the difficulty of [final exams] increased, declined, or stayed about the same? If the [final exams] have changed in difficulty, when did the changes occur? We received responses from $86 \%$ of the messaged faculty. No faculty indicated that tests had become more difficult, $58 \%$ indicated that difficulty had remained about the same or become easier over time, and $42 \%$ either did not know, could not tell, or gave an answer that was not responsive to the question.

${ }^{34}$ In our email survey to course representatives we asked: "Are [final exams] graded automatically (e.g. computer, scan, multiple choice), by a student's instructor, or by team?" In response, $42 \%$ of faculty indicated that finals were graded automatically or in teams, 33\% indicated that finals were graded part automatically and part by instructor, and $25 \%$ indicated that finals were graded by instructors.
} 
happening in their responses to a survey we distributed, we provide a stronger test of whether improving grades over time could be explained by increased learning. We analyze the relationship between year of entry and GPA in two required freshman science courses - courses where the final exams are comprehensive, are graded by machine or in teams, and change little or not at all from one year to the next. ${ }^{35}$ Specifically, we examined every final exam, question by question, from 2001-2012 and found that in both required courses 9 out of 12 of the final exams given were identical to an exam given in another year. ${ }^{36}$ This setting allows for a very close approximation of the ideal test for grade inflation.

In column 6 of Table 8 we control for course fixed effects, demographic characteristics, and final exam scores in these two science courses and find that a year later entry corresponds to a large and statistically significant 0.060-point increase in GPA. In column 7 we additionally control for an exact exam fixed effect and find that a year later entry corresponds to a 0.053-point increase in GPA. In column 8 our results are essentially unchanged when we replace the final exam control with a control for test-specific final exam scores. Students with the exact same score on the exact same final exam earned better grades in later years. Our findings that grades are increasing over time, even when student characteristics and performance on identical comprehensive final exams are accounted for, suggests that standards for degree receipt are easing over time at the Public Liberal Arts College.

\footnotetext{
${ }^{35}$ Additionally, the structure of these courses have not significantly changed over time, with the final exams having constant point values over time and accounting for between $20-26 \%$ of the total grade grades in each course.

36 In each year, in both courses, a majority of questions from the final exam were identical to questions asked in the prior year's final exam. Furthermore, in the first course enrolling cohorts in 2002, 2007, 2009, 2010, and 2012 were given identical tests to the prior cohort. In the second course, enrolling cohorts in 2003, 2005, 2009, 2011, and 2012 were given identical tests to the prior cohort.
} 
While the evidence at Public Liberal Arts College is specific to that university, we believe that it is likely informative of broader trends. Public Liberal Arts College has similar graduation and GPA trends to the NELS:88/ ELS:2002 samples.

First, in Panel B of Table 5 we find that, after controlling for observable characteristics, a one grade-point increase is associated with a 21 percentage point increase in the probability of graduation in both the early (2001-2003) and late (20102012) entering Public Liberal Arts College cohorts. This is nearly identical to the 24 and 22 percentage point increases estimated in the NELS:88 and ELS:2002 samples in Panel A of Table 5. Second, Figure A2 shows similar non-linear relationships between GPA and graduation in both early and late Public Liberal Arts College cohorts to the relationships found in the NELS:88 and ELS:2002 samples (Figure A2): in each of the four samples, the change in the probability of graduation is largest for GPAs between 1.0 and 2.5. Finally, in Figure A4 we show that increases in GPA between the early and late Public Liberal Arts College cohorts are similar to those found between NELS:88 and ELS:2002, as shown in Figures 4 and A3.

\section{Adding GPA to the decomposition}

Given the evidence that GPA is changing over time and that GPA is predictive of graduation, we show how much of the change in graduation rates can be explained by changes in GPA. We add GPA to the decomposition exercise since it is increasing over time and predictive of graduation. We note that this is a "bad control" because it is endogenous to the type of college a student attends among other things. We include it in the decomposition analysis in the spirit of looking for a mediator rather than interpreting the effects of changing GPA causally. Table 9 presents the same decomposition exercise with one notable change to the specification used by BLT-the 
inclusion of first-year GPA. ${ }^{37}$ The addition of GPA substantially increases the change in graduation rate due to observables. ${ }^{38}$ For the full sample, the change due to observables (including first-year GPA) is 2.49 percentage points or 66 percent of the total change. The change explained by GPA alone is 3.57 or 95 percent of the observed change. ${ }^{39}$ The total change due to observables grows substantially with the inclusion of GPA at all schools. At public non-top 50s (the largest category) observables explain 57 percent of the change in graduation. First-year GPA is an imperfect proxy for grade inflation but still explains a substantial portion of the observed change.

A related explanation is that many schools are more efficient in producing degrees. For example, improved access to technology (Farlie and London, 2012), the emergence of residential learning communities (Hotchkiss, Moore, and Pitts, 2006), expansion of experiential learning approaches (Hawtrey, 2007), and other pedagogical advancements could have improved educational efficiency over this time. Measuring efficiency in producing graduates is very difficult, especially if quality is not fixed. While our evidence suggests that increased learning cannot explain rising grades or graduation rates at Public Liberal Arts College, it is possible that increased learning could explain some of the increases in other settings. However, the gains in efficiency

\footnotetext{
${ }^{37}$ Comparing the results from Table 4 and Table 9 directly is difficult because we use different regressions in each table. As a result, the change in graduation rates explained by each non-GPA factor differs slightly. However, the change in graduation rates due to non-GPA factors tell a very similar story in both settings.

${ }^{38}$ Although BLT do not include first-year GPA in their decomposition, it is unlikely to have similar explanatory power in their context due to trends in GPAs during the timeframe they study. Rojstaczer and Healy (2010) document little change in GPAs between the early 1970s (NLS:72 cohort) and early 1990s (NELS:88 cohort). In contrast, Rojstaczer and Healy document significant increases in GPA in subsequent years.

${ }^{39}$ We also can add GPA nonlinearly. We do this by replacing the linear effect of GPA with indicators for bins of GPA that are .5 GPA points wide in Table A6. When we do this, the results are substantively similar with GPA explaining slightly less of the change in graduation rates overall. GPA has less explanatory power at selective schools when discretizing first-year GPA. However, we do not allow the coefficients for GPA bins to vary by school type for tractability. This assumes that the same ranges of GPA are predictive for graduation across school types which may not be true.
} 
would have to overcome the trends we have documented including declining resources, increasing tuition, stagnant student preparation, increasing student employment, decreasing study time, etc. Given the steady and large increases in graduation in the face of these trends predicting graduation declines, we find that grade inflation is likely to be at least part of the explanation.

\subsection{Major Choice and Other Explanations}

Another possible explanation for increasing college graduation rates is student's major choice if students have moved to majors with higher graduation rates. Table 3 shows that the graduation rate of majors chosen by students stayed very similar or slightly declined; that is, students chose majors that had slightly lower graduation rates in ELS:2002 than they did in NELS:88. To isolate the effect of major choice, we fix major graduation rates at their NELS:88 levels and apply them to the actual major choices made in ELS:2002. We find that predicted graduation rates and actual graduation rates are very similar. In results not presented, we add a student's major graduation rate to the decomposition and find it does not explain much of the change in graduation rates.

Another potential explanation for our results is that colleges may have increased their focus on graduation rates by increasing programs and funding for student success initiatives. This is a difficult mechanism to test. First, we look at staff expenditures using data from IPEDS. Institutions report the spending of "other professional staff" "for the primary purpose of performing academic support, student service, and institutional support." This measure likely includes staff working on student success initiatives but also includes things that are unlikely to be related to student success. Trends in this variable can be seen in Table A3. Overall, spending on support programs cannot explain much of the increase in graduation rates because they are largely the same across cohorts. However, there are some increases at more selective schools in measures of "other professional staff" suggesting that these increases have scope to explain some 
of the increase in graduation rates at these schools. Similarly, we see an overall decrease in instructional expenditures which represents an alternative way to measure investment (relative to student/faculty ratios). Private schools did see some increase in instructional spending which could explain some of the increase in graduation. However, when we use this measure instead of student to faculty ratios, we find qualitatively similar results.

We are interested in heterogeneity by school type but are somewhat limited by the size of the sample for some school types. As we noted, the increase in graduation rates across NELS:88 and ELS:2002 is statistically significant overall, for public top 50s, public non-top 50s (at the ten percent level), and community colleges. We are limited in our ability to assess the relative importance of various factors across school types because there are not statistically significant changes in graduation rates for all school types. That said, if anything, GPA has larger explanatory power for public universities than for private universities.

\section{Discussion and Conclusion}

In this paper we carefully document that college graduation rates have increased from the 1990s to 2010. This represents a change in the pattern documented by BLT. In contrast to BLT, we do not find that traditional measures of student characteristics or colleges explain much of the change in graduation rates. Rather, we show that student GPAs increased over this time period and that this change can explain much of the increase in graduation rates.

We present evidence from national survey data and detailed administrative data from 9 large public universities that the increase in GPA is not explained by observable student or institution characteristics. In our Public Liberal Arts College sample, we find that grades are increasing after controlling for comprehensive final exam performance. 
Furthermore, in two required science courses, we find that grades are rising over time even when comparing students who receive the same score on identical exams. Combined with existing work on trends in student study, college preparation, labor supply, the price of college, and resources per student, our evidence suggests that grade inflation is contributing to increasing grades and graduation rates.

Why did grade point averages increase from the 1990s to 2010? One likely candidate is the recent policy focus on college completion rates. As schools face increased scrutiny and, in some cases, increased funding incentives, they may respond by taking action to increase graduation rates. Changing standards for degree receipt is a low-cost way to increase graduation rates. In support of this interpretation, the increase in graduation rates is concentrated at public schools that have seen more of their funding tied to graduation. However, we find that grades have risen at all school types aside from for-profit colleges.

Further, spending per student declined suggesting that colleges did not increase spending to help students graduate. Additionally, instructors and departments have incentives to raise grades to improve their student evaluations and enrollments respectively.

While many are likely to decry the trend in rising grades, the welfare implications of this rise are ambiguous. In either a human capital or signaling model of education, declining standards of degree receipt as indicated by rising college grades would predict that the reduced average skill of graduates would lead to a declining college wage premium. ${ }^{40}$ However, there is evidence that there has been increasing

\footnotetext{
${ }^{40}$ It is not clear how grade inflation would affect the earnings return to GPA for college graduates. If grade inflation were uniform with every student's GPA increased by the same amount, GPAs would become more compressed as high GPAs are censored. This would imply that a 1 point increase in GPA represents a larger change in performance which would drive up the returns to GPA. However, if the grade inflation is not uniform, it could reduce the signaling value of GPA in the labor market which would reduce the earnings return to GPA.
} 
demand for college-educated workers (Autor, Katz, and Kearney, 2008) and decreased standards to degree receipt could act to meet this demand and increase economic growth, even if new college graduates have less skill on average than prior cohorts.

Further complicating the interpretation of grade inflation, rising grades may affect major choice and the subsequent earnings returns to education. Majors that see greater levels of grade inflation are likely to attract more students (Butcher, McEwan, Weerapana, 2014). Because majors with traditionally low GPAs, such as those in STEM fields, may have the most room to increase grades, rising grades may lead to an increase in the number of students in these majors.

Finally, if student effort is not fixed, declining standards have ambiguous predictions for overall student effort and subsequent learning. For example, if the objective of most students is to avoid the risk of failure and academic probation, then decreasing standards are likely to reduce effort and learning for all students except those on the margin of passing. However, if students seek to maximize their GPA, decreasing standards may increase learning as decreasing standards increase the GPA returns to effort for all but the top-performing ( $\mathrm{A}$ or $\mathrm{A}+$ ) students. Given the ambiguous implications of grade inflation in higher education and social welfare, future work should consider the effects of grade inflation on learning, major choice, the decision to enroll in graduate school, the skill composition of the workforce, and the college wage premium. 


\section{References}

Archibald, R. B., Feldman, D. H., \& McHenry, P. (2015). A quality-preserving increase in four-year college attendance. Journal of Human Capital, 9(3), 265-297.

Arcidiacono, P., Aucejo, E., Maurel, A., \& Ransom, T. (2016). College attrition and the dynamics of information revelation (No. w22325). National Bureau of Economic Research.

Ashworth, J., \& Ransom, T. (2019). Has the College Wage Premium Continued to Rise? Evidence from Multiple US Surveys. Economics of Education Review, 69, 149-154.

Autor, D. H., Katz, L. F., \& Kearney, M. S. (2008). Trends in US wage inequality: Revising the revisionists. Review of Economics and Statistics, 90(2), 300-323.

Babcock, Philip, and Mindy Marks. "The falling time cost of college: Evidence from half a century of time use data." Review of Economics and Statistics 93, no. 2 (2011): 468-478.

Bailey, Martha J., and Susan M. Dynarski. "Inequality in Postsecondary Education" In G.J. Duncan and R.J. Murnane (eds.), Whither Opportunity? Rising Inequality, Schools, and Children's Life Chances. (Russell Sage: New York, New York, September 2011).

Bar, T., Kadiyali, V., \& Zussman, A. (2009). Grade information and grade inflation: The Cornell experiment. Journal of Economic Perspectives, 23(3), 93-108.

Bar, T., Kadiyali, V., \& Zussman, A. (2012). Putting grades in context. Journal of Labor Economics, 30(2), 445-478.

Barr, Andrew. "Fighting for Education: Veterans and Financial Aid" (2019). Journal of Labor Economics, 37(2), 509-544.

Bettinger, Eric, Oded Gurantz, Laura Kawano, and Bruce Sacerdote. The long run impacts of merit aid: Evidence from California's Cal Grant. (2019) American Economic Journal: Economic Policy.

Black, S. E., Denning, J. T., \& Rothstein, J. (2020). Winners and Losers? The Effect of Gaining and Losing Access to Selective Colleges on Education and Labor Market Outcomes (No. w26821). National Bureau of Economic Research.

Blagg, K., \& Chingos, M. M. (2016). Varsity Blues. Research Report, Urban Institute. 
Bleemer, Z. (2018). Top percent policies and the return to postsecondary selectivity. Available at SSRN 3272618.

Blinder, A. S. (1973). Wage discrimination: reduced form and structural estimates. Journal of Human resources, 436-455.

Boleslavsky, R., \& Cotton, C. (2015). Grading standards and education quality. American Economic Journal: Microeconomics, 7(2), 248-79.

Bound, John, Michael F. Lovenheim, and Sarah Turner. "Why have college completion rates declined? An analysis of changing student preparation and collegiate resources." American Economic Journal: Applied Economics 2.3 (2010): 129-57.

Bound, John, Michael F. Lovenheim, and Sarah Turner. "Increasing time to baccalaureate degree in the United States." Education Finance and Policy 7.4 (2012): 375424.

Butcher, K. F., McEwan, P. J., \& Weerapana, A. (2014). The effects of an anti-gradeinflation policy at Wellesley College. Journal of Economic Perspectives, 28(3), 189-204.

Castleman, Benjamin L., and Bridget Terry Long. "Looking beyond enrollment: The causal effect of need-based grants on college access, persistence, and graduation." Journal of Labor Economics 34, no. 4 (2016): 1023-1073.

Cohodes, S. R., \& Goodman, J. S. (2014). Merit aid, college quality, and college completion: Massachusetts' Adams scholarship as an in-kind subsidy. American Economic Journal: Applied Economics, 6(4), 251-85.

CollegeBoard. "Trends in College Pricing 2017" Trends in Higher Education Series (2017).

Deming, David J. "Increasing college completion with a federal higher education matching grant." The Hamilton Project, Policy Proposal 3 (2017).

Deming, David J., Claudia Goldin, and Lawrence F. Katz. "The for-profit postsecondary school sector: Nimble critters or agile predators?" Journal of Economic Perspectives 26, no. 1 (2012): 139-64.

Deming, David J., Claudia Goldin, Lawrence F. Katz, and Noam Yuchtman. "Can online learning bend the higher education cost curve?" American Economic Review 105, no. 5 (2015): 496-501. 
Deming, David J., and Christopher R. Walters. "The Impact of State Budget Cuts on US Postsecondary Attainment." (2017) NBER Working Paper No 2373.

Denning, Jeffrey T. (2019) “Born Under a Lucky Star: Financial Aid, College Completion, and Credit Constraints." Journal of Human Resources 54(3).

Denning, Jeffrey T., Benjamin M. Marx, and Lesley J. Turner. (2019) "ProPelled: The Effects of Grants on Graduation, Earnings, and Welfare." American Economic Journal: Applied Economics 11(3), 193-224.

Denning, Jeffrey T., Eric R. Eide, Kevin J. Mumford, Richard W. Patterson, and Merrill Warnick. 2021. "Public Liberal Arts Administrative Student Data for: Why Have College Completion Rates Increased? An Analysis of Rising Grades."

Fairlie, R. W., \& London, R. A. (2012). The effects of home computers on educational outcomes: Evidence from a field experiment with community college students. The Economic Journal, 122(561), 727-753.

Gershenson, S. (2018). Grade Inflation in High Schools (2005-2016).

Goodman, Joshua, Michael Hurwitz, and Jonathan Smith. (2017). College Access, Initial College Choice and Degree Completion. Journal of Labor Economics 35(3), 829-867.

Griffith, A., Sovero V. (2019) “Under Pressure: Grade Inflation by Academics” Working Paper.

Hawtrey, K. (2007). Using experiential learning techniques. The Journal of Economic Education, 38(2), 143-152.

Hess, F. M., \& Hatalsky, L. E. (2018). Elevating College Completion. American Enterprise Institute.

Hillman, N. W., Hicklin Fryar, A., \& Crespín-Trujillo, V. (2018). Evaluating the impact of performance funding in Ohio and Tennessee. American Educational Research Journal, 55(1), 144-170.

Hillman, N. W., Tandberg, D. A., \& Fryar, A. H. (2015). Evaluating the impacts of "new" performance funding in higher education. Educational Evaluation and Policy Analysis, 37(4), 501-519.

Hillman, N. W., Tandberg, D. A., \& Gross, J. P. (2014). Performance funding in higher education: Do financial incentives impact college completions?. The Journal of Higher Education, 85(6), 826-857.

Hotchkiss, J. L., Moore, R. E., \& Pitts, M. M. (2006). Freshman learning communities, college performance, and retention. Education economics, 14(2), 197-210. 
Jaeger, David A. and Marianne E. Page. (1996). “Degrees Matter: New Evidence on Sheepskin Effects in the Returns to Education." The Review of Economics and Statistics, Vol. 78, No. 4, pp. 733-740.

Long, B.T. (2018) "The College Completion Landscape: Trends, Challenges, and Why it Matters" Third Way. May 25, 2018.

Krautmann, A. C., \& Sander, W. (1999). Grades and student evaluations of teachers. Economics of Education Review, 18(1), 59-63.

Langbein, L. (2008). Management by results: Student evaluation of faculty teaching and the mis-measurement of performance. Economics of Education Review, 27(4), 417-428.

National Center for Education Statistics (2013). “The Nation's Report Card: Trends in Academic Progress 2012."

National Center for Education Statistics (2018). "Digest of Education Statistics, 2016."

National Center for Education Statistics (2002) "Educational Longitudinal Study of 2002 (ELS:2002)."

National Center for Education Statistics (1988) "National Education Longitudinal Study of 1988 (NELS:88)."

National Center for Education Statistics, Integrated Postsecondary Education Data System (IPEDS), .

Oaxaca, R. (1973). Male-female wage differentials in urban labor markets. International Economic Review, 693-709.

Ohland, Matthew and Russell Long. 2020. "MIDFIELD Data" Multiple-Institution Database for Investigating Engineering Longitudinal Development, Purdue University, West Lafayette, IN. https://engineering.purdue.edu/MIDFIELD/index.html (version: 2020-03-16-fix9).

Oreopoulos, Philip and Petronijevic, Uros. (2013). Making College Worth it: A Review of the Returns to Higher Education. The Future of Children. Vol. 23, No. 1.

Ost, Ben, Pan, Victor, and Douglas A. Webber. (2018). "The Returns to College Persistence for Marginal Students: Regression Discontinuity Evidence from University Dismissal Policies." Journal of Labor Economics. 
Pattison, E., Grodsky, E., \& Muller, C. (2013). Is the sky falling? Grade inflation and the signaling power of grades. Educational Researcher, 42(5), 259-265.

Rojstaczer, S., \& Healy, C. (2010). Grading in American colleges and universities. Teachers College Record, 4, 1-6.

Rojstaczer, S., \& Healy, C. (2012). Where A is ordinary: The evolution of American college and university grading, 1940-2009. Teachers College Record, 114(7), 1-23.

Steven Ruggles, Sarah Flood, Ronald Goeken, Josiah Grover, Erin Meyer, Jose Pacas, and Matthew Sobek. IPUMS USA: Version 9.0 [dataset]. Minneapolis, MN: IPUMS, 2019. https://doi.org/10.18128/D010.V9.0

Schudde, L., \& Scott-Clayton, J. (2016). Pell grants as performance-based scholarships? An examination of satisfactory academic progress requirements in the nation's largest need-based aid program. Research in Higher Education, 57(8), 943-967.

Scott-Clayton, Judith. "On money and motivation a quasi-experimental analysis of financial incentives for college achievement." Journal of Human Resources 46, no. 3 (2011): 614-646.

Scott-Clayton, Judith. "What explains trends in labor supply among US undergraduates?" National Tax Journal 65, no. 1 (2012): 181.

Shapiro, D., Dundar, A., Huie, F., Wakhungu, P.K., Yuan, X., Nathan, A. \& Bhimdiwali, A. (2017, December). "Completing College: A National View of Student Completion Rates - Fall 2011 Cohort" (Signature Report No.14)". Herndon, VA: National Student Clearinghouse Research Center.

Tandberg, D. A., \& Hillman, N. W. (2014). State higher education performance funding: Data, outcomes, and policy implications. Journal of Education Finance, 222-243. Valletta, R. G. (2016). Recent flattening in the higher education wage premium: polarization, skill downgrading, or both? (No. w22935). National Bureau of Economic Research.

Zimmerman, Seth D. (2014). The Returns to College Admission for Academically Marginal Students. Journal of Labor Economics 32(4), 711-754. 
Figures and Tables

Figure 1: Ratio of BA / Some College among 25 year-olds

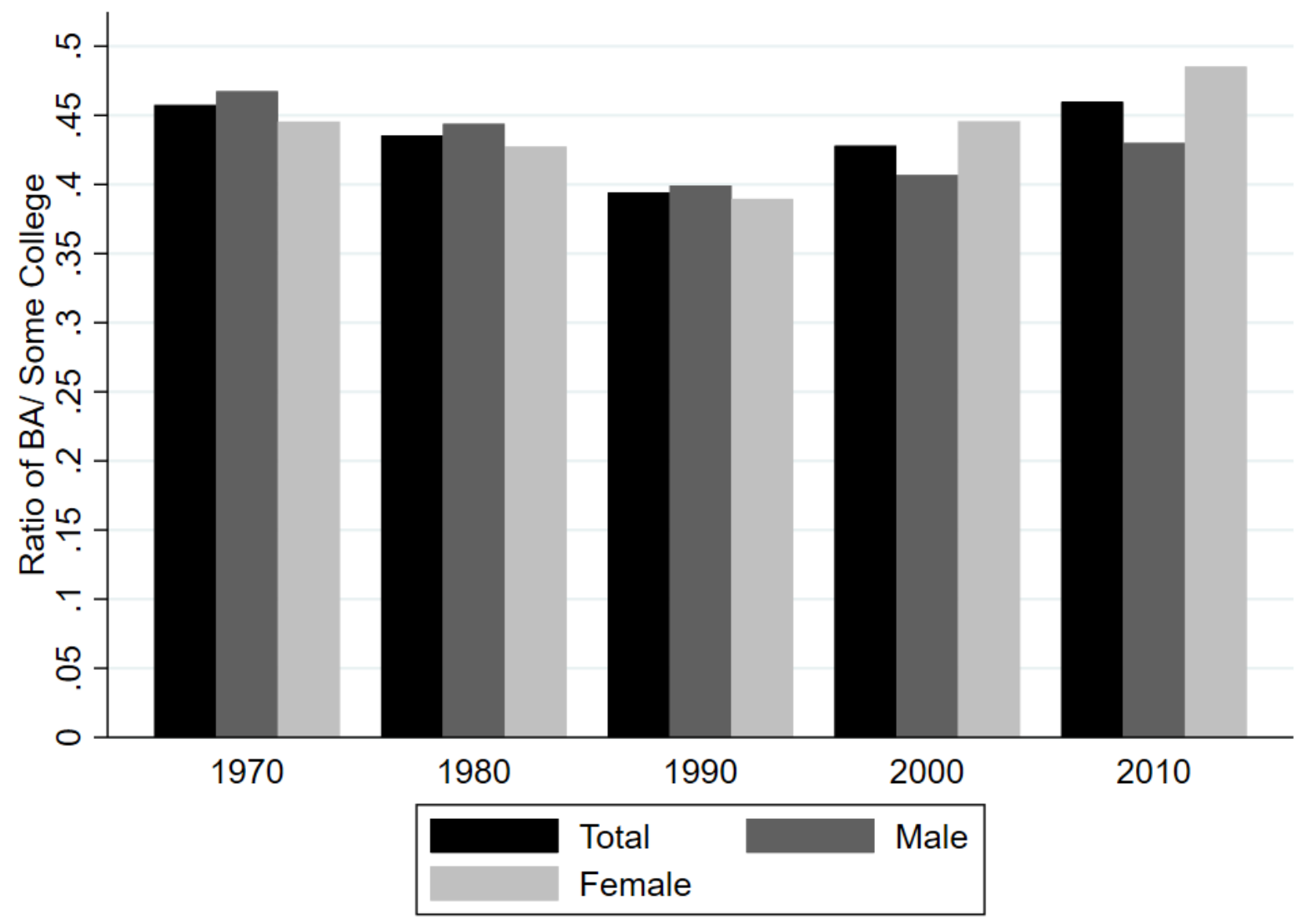

Notes: Data come from the decennial census downloaded from the Integrated Public Use Microdata series database at IPUMS USA. Following BLT, we calculated the ratio of 25-year-olds having a bachelor's degree to 25-year-olds with at least some college completed. 
Figure 2: Graduate Rates by College Sector

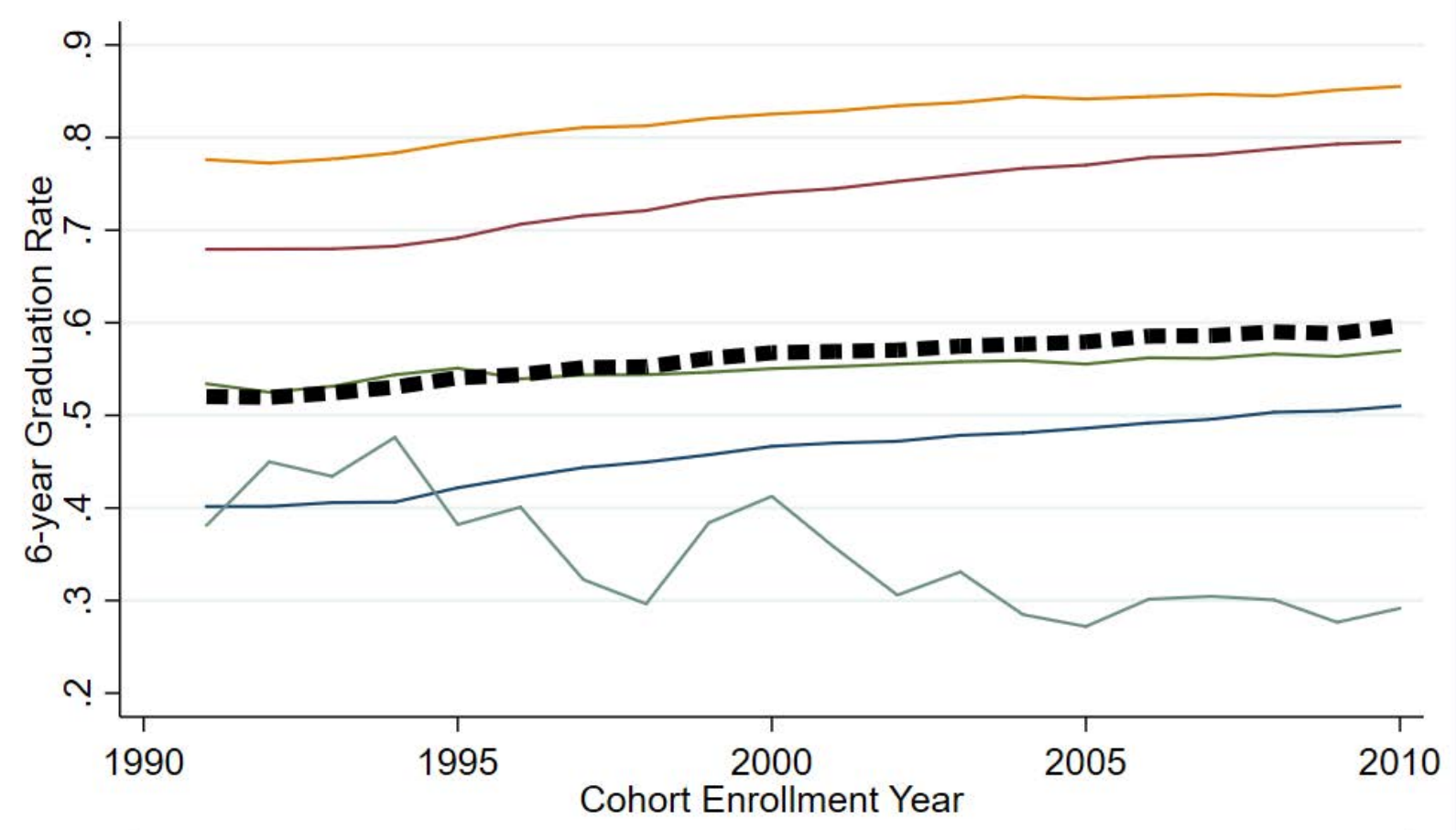

\begin{tabular}{ll}
- Non-Top 50 public & Top 50 public \\
Non-Profit, non-selective & Non-Profit, highly selective \\
For-Profit & $\mathbf{m}$. Aggregate \\
\hline
\end{tabular}

Note: Source: IPEDS. This figure plots the average six-year graduation rate for different institution types. Cohort enrollment year refers to the year that students were first enrolled. See Section 4 in the text for a detailed description of how institutions are assigned to a type. Schools that were predominantly online are excluded for all cohorts. These rates were calculated using only students who were full-time, first-time degree seekers in their respective entry years. 


\section{Figure 3: Nonlinear Relationship between First-Year GPA and Graduation}
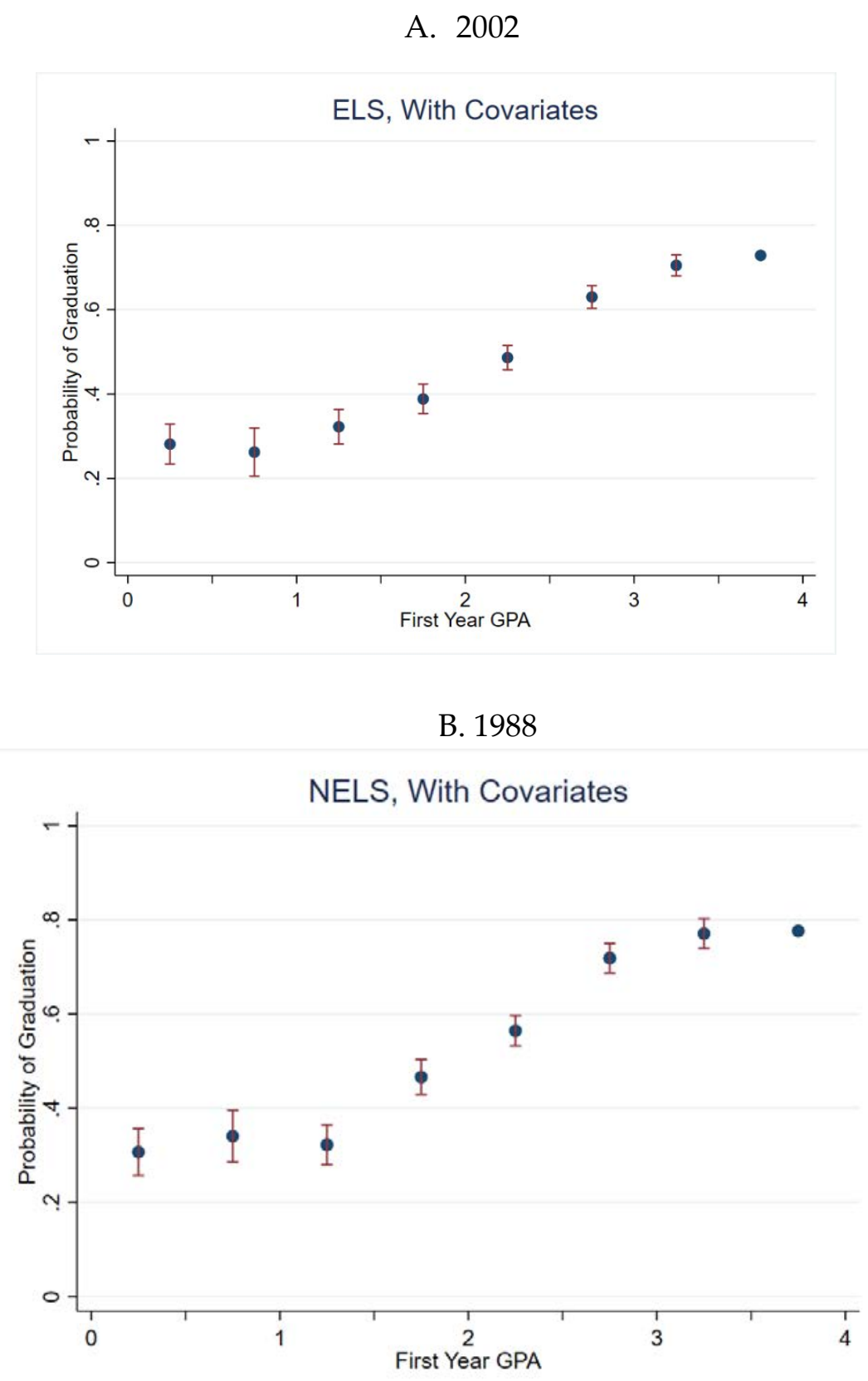

Note: This shows the relationship between GPA and graduation. Each point represents the coefficient on an indicator for GPA window (0 to .5, .5 to 1, ...). The top bin is calculated using the constant in that regression. Student characteristics including gender, race, family income, and pre-collegiate math test scores are controlled for in these regressions. 
Figure 4: Smoothed CDF of First-Year GPA for 1988 and 2002 by Institution Type

A. Public Top 50

Public Top 50 Schools

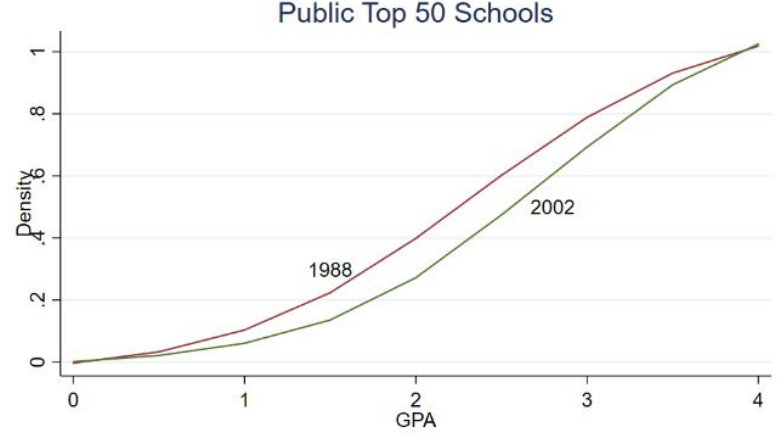

B. Public Non Top 50

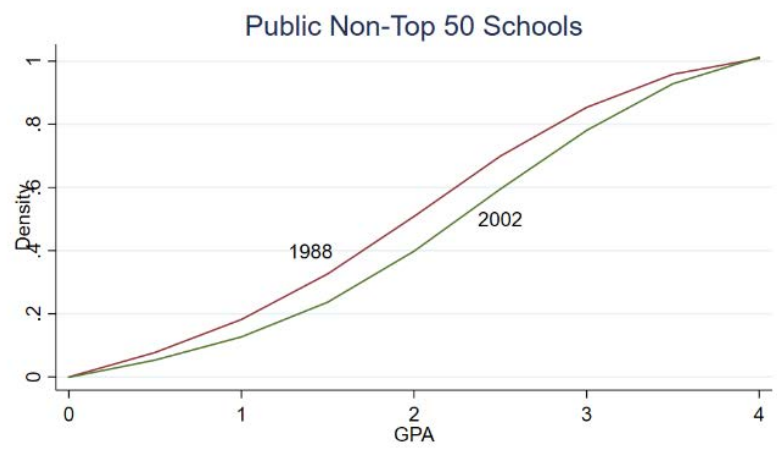

C. Private Selective

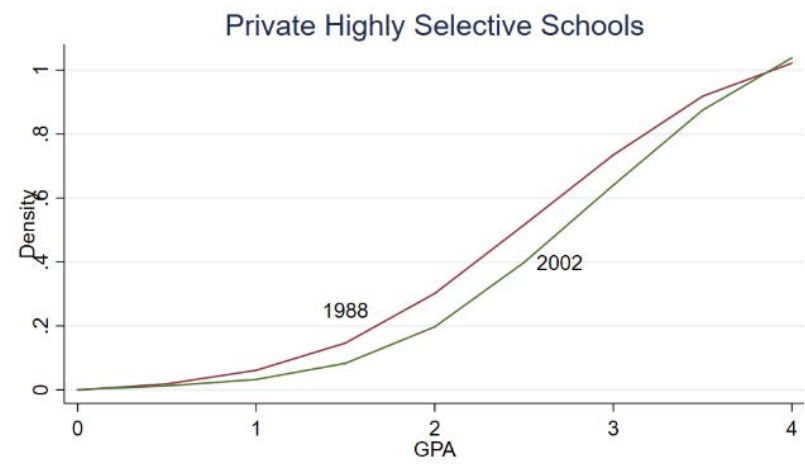

D. Private Less Selective

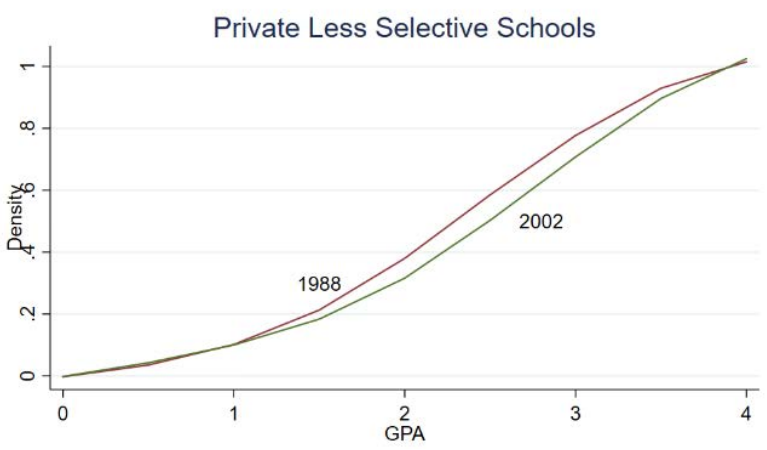

E. Community College

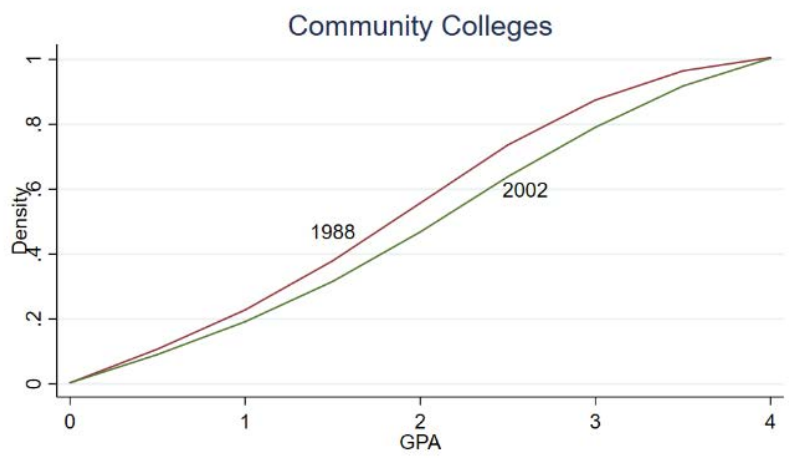

F. For Profit

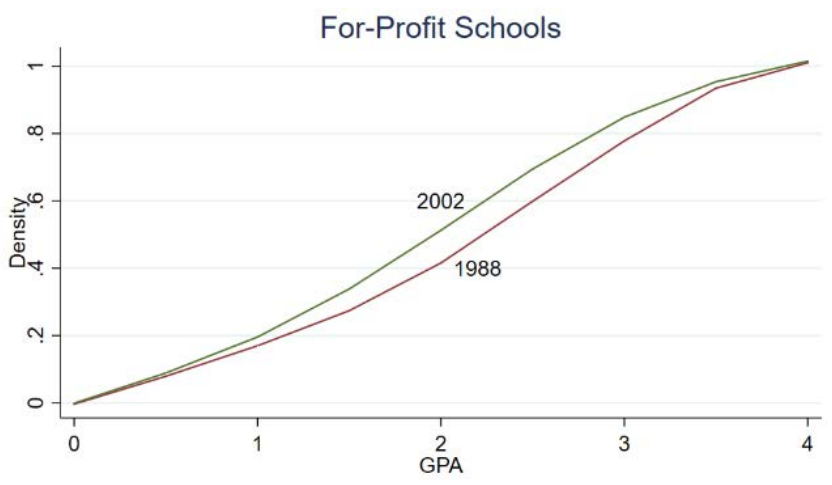

Notes: This plots a smoothed cdf of GPAs from NELS:88 and ELS:2002 separately by institution type. 1988 refers to NELS:88 and 2002 refers to ELS:2002. 
Table 1: Changes in College Graduation Rates

\begin{tabular}{cccc} 
Sample & 1988 & 2002 & Difference \\
\hline Full Sample & 48.7 & 52.5 & 3.77 \\
& & & $(1.71)$ \\
Initial Institution Type & & & \\
Total Four-year Public & 63.3 & 67.7 & 4.49 \\
& & & $(2.38)$ \\
Non-top 50 Public & 56.1 & 61.0 & 4.89 \\
& & & $(2.59)$ \\
Top 50 Public & 82.1 & 90.7 & 8.57 \\
& & & $(2.57)$ \\
Total Four-year Private & 78.4 & 77.2 & -1.14 \\
& & & $(2.30)$ \\
Less Selective Private & 72.3 & 71.2 & -1.05 \\
& & & $(2.96)$ \\
Highly Selective Private & 90.5 & 92.2 & 1.66 \\
& & & $(2.76)$ \\
Total Community College & 19.6 & 24.3 & 4.77 \\
& & & $(1.71)$ \\
For-Profit College & 25.2 & 24.7 & -0.42 \\
& & & $(8.92)$ \\
All Non-Profit Colleges & 48.8 & 53.0 & 4.18 \\
& & & $(1.72)$ \\
All Four-Year Colleges & 68.3 & 70.6 & 2.31 \\
& & & $(1.85)$ \\
\hline
\end{tabular}

Note: 1988 refers to NELS:88 and 2002 refers to ELS:2002.This table describes the graduation rates for college enrollees by school type for the 1988 and 2002. The row for All Non-Profit Colleges includes private and public colleges and excludes for-profit colleges. 
Table 2: Changes in Initial College Attended

\begin{tabular}{ccccccc} 
& \multicolumn{2}{c}{ Total } & \multicolumn{2}{c}{ Men } & \multicolumn{2}{c}{ Women } \\
& 1988 & 2002 & 1988 & 2002 & 1988 & 2002 \\
\cline { 2 - 7 } Percent of HS grads Attending College & 69.3 & 78.3 & 66.9 & 74.2 & 71.8 & 84.1 \\
& & & & & & \\
Distribution of Enrollment by Type of Institution & & & & & & \\
Total 4-year Public & 39.9 & 42.2 & 39.7 & 42.7 & 40.1 & 41.7 \\
Non-top 50 Public & 28.9 & 32.6 & 28.3 & 33.2 & 29.6 & 32.1 \\
Top 50 Public & 10.9 & 9.6 & 11.4 & 9.4 & 10.5 & 9.6 \\
Total 4-year Private & 20.0 & 18.4 & 18.0 & 18.0 & 21.8 & 18.8 \\
Less Selective Private & 13.3 & 13.2 & 11.4 & 12.2 & 15.1 & 14.0 \\
Highly Selective Private & 6.7 & 5.2 & 6.7 & 5.8 & 6.7 & 4.7 \\
Total Community College & 39.8 & 37.2 & 41.8 & 36.6 & 37.9 & 37.6 \\
For Profit Colleges & 0.4 & 2.3 & 0.5 & 2.7 & 0.3 & 1.9 \\
\hline
\end{tabular}

Note: This table describes the change in the fraction of students attending college within two years of expected high school graduation and initial college attended for the 1988 and 2002 Educational Longitudinal Study cohorts. 
Table 3: Summary Statistics 1988 and 2002

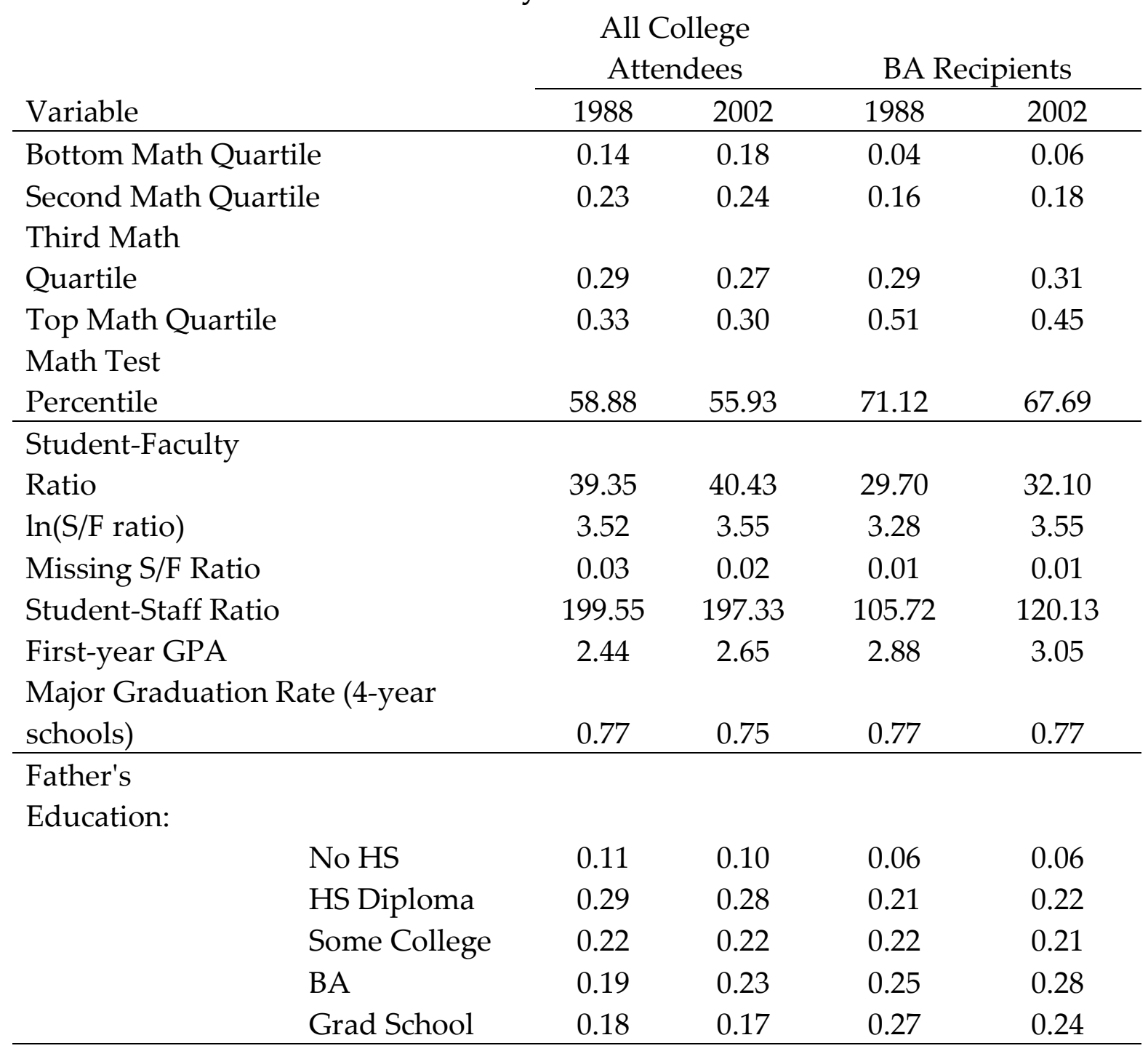

Mother's

Education: 


\begin{tabular}{llllll} 
& No HS & 0.10 & 0.09 & 0.05 & 0.05 \\
& HS Diploma & 0.34 & 0.28 & 0.26 & 0.23 \\
& Some College & 0.25 & 0.26 & 0.27 & 0.25 \\
& BA & 0.18 & 0.23 & 0.25 & 0.28 \\
& Grad School & 0.12 & 0.15 & 0.17 & 0.19 \\
\hline Parental Income: & & & & & \\
& $<10000 / 15000$ & 0.06 & 0.06 & 0.03 & 0.04 \\
& $<20000 / 25000$ & 0.10 & 0.09 & 0.06 & 0.06 \\
& $<25000 / 35000$ & 0.07 & 0.11 & 0.06 & 0.07 \\
& $<35000 / 50000$ & 0.13 & 0.18 & 0.10 & 0.16 \\
& $<50000 / 75000$ & 0.22 & 0.23 & 0.20 & 0.23 \\
& $>50000 / 75000$ & 0.42 & 0.33 & 0.55 & 0.44 \\
\hline Race/Ethnicity: & & & & & \\
& Asian & 0.05 & 0.04 & 0.06 & 0.06 \\
& Hispanic & 0.10 & 0.12 & 0.06 & 0.07 \\
& African & & & & \\
& American & 0.11 & 0.11 & 0.07 & 0.08 \\
& White & 0.75 & 0.73 & 0.81 & 0.79 \\
\hline Male & 0.49 & 0.46 & 0.45 & 0.44 \\
\hline Number of Observations & 7770 & 8640 & 4110 & 4970 \\
\hline
\end{tabular}

Note: 1988 refers to NELS:88 and 2002 refers to ELS:2002. This table presents summary statistics from 1988 and 2002 for college enrollees and graduates. Math test Quartiles come from pre-collegiate assessment tests. The number of observations is rounded to the nearest 10 to comply with the data use agreement. 
Table 4: Decomposition Exercise, Changes in College Graduation, BLT Specification

\begin{tabular}{|c|c|c|c|c|c|c|c|}
\hline & $\begin{array}{c}\text { Full } \\
\text { Sample }\end{array}$ & $\begin{array}{c}\text { Public } \\
\text { non-top } \\
50\end{array}$ & $\begin{array}{l}\text { Public } \\
\text { top } 50\end{array}$ & $\begin{array}{c}\text { Private } \\
\text { Less } \\
\text { Selective }\end{array}$ & $\begin{array}{c}\text { Private } \\
\text { Highly } \\
\text { Selective }\end{array}$ & $\begin{array}{l}\text { Community } \\
\text { College }\end{array}$ & $\begin{array}{c}\text { For- } \\
\text { Profit } \\
\text { Schools }\end{array}$ \\
\hline NELS:88 & 48.73 & 56.12 & 82.15 & 72.26 & 90.50 & 19.56 & 25.15 \\
\hline ELS:2002 & 52.50 & 61.01 & 90.71 & 71.21 & 92.16 & 24.33 & 24.73 \\
\hline Total Change & 3.77 & 4.89 & 8.57 & -1.05 & 1.66 & 4.77 & -0.42 \\
\hline Change due to Observables & -1.92 & -4.45 & -0.42 & -0.61 & 3.60 & -0.81 & 9.43 \\
\hline \multicolumn{8}{|l|}{ Change due to Student } \\
\hline Characteristics & -1.64 & -2.64 & -0.43 & -0.63 & 2.68 & -0.84 & 9.43 \\
\hline $\begin{array}{l}\text { Math Test Percentile } \\
\text { Other Student }\end{array}$ & -1.26 & -2.04 & 0.15 & -0.78 & 0.26 & -0.96 & 0.26 \\
\hline Characteristics & -0.39 & -0.60 & -0.58 & 0.15 & 2.42 & 0.12 & 9.17 \\
\hline \multicolumn{8}{|l|}{ Change due to Supply-Side } \\
\hline Factors & -0.28 & -1.82 & 0.00 & 0.02 & 0.92 & 0.03 & 0.00 \\
\hline Student/Faculty Ratios & -0.28 & -1.82 & 0.00 & 0.02 & 0.92 & 0.03 & 0.00 \\
\hline Initial School Types & 0.00 & & & & & & \\
\hline Residual & 5.69 & 9.35 & 8.99 & -0.44 & -1.94 & 5.58 & -9.86 \\
\hline
\end{tabular}

Notes: These differences were created by finding the difference between observed ELS:2002 graduation rates and simulated ELS:2002 graduation rates using distributions of NELS:88 variables. Math test percentiles come from pre-collegiate assessment tests. Change due to observables uses the NELS:88 distribution for all observable variables, that is, how much do all observed variable predict the change in graduation. Change due to math test percentile uses the NELS:88 distribution for only math test percentile, and observed ELS:2002 distributions for all other observable variables. Similarly, change due to student-faculty ratios and initial school types use the NELS:88 distribution for only student-faculty ratios and initial school types, respectively. The change due to supply-side factors is the sum of 
change due to student-faculty ratios and change due to initial school types. The change due to student characteristics is the difference between change due to observables and change due to supply side factors. The change due to other characteristics is the difference between change due to student characteristics and the change due to math test percentile. The residual is the difference between the total change and the difference due to observables. 
Table 5: Relationship between Graduation and GPA

\section{A. NCES}

\begin{tabular}{lccccccccc} 
& 1988 & 2002 & 1988 & 2002 & 1988 & 2002 & 1988 & 2002 \\
\hline GPA & 0.30 & 0.27 & 0.24 & 0.22 & 0.24 & 0.22 & 0.23 & 0.20 \\
& $(0.010)$ & $(0.007)$ & $(0.011)$ & $(0.009)$ & $(0.011)$ & $(0.009)$ & $(0.012)$ & $(0.012)$ \\
& & & & & & & & & \\
Student Characteristics & & & $X$ & $X$ & $X$ & $X$ & $X$ \\
Major Graduation Rates & & & & & $X$ & $X$ & & $X$ \\
Major Fixed Effects & & & & & & & $X$
\end{tabular}

\begin{tabular}{lcccc} 
& $2001-$ & $2010-$ & $2001-$ & $2010-$ \\
B. Public Liberal Arts College & 2003 & 2012 & 2003 & 2012 \\
\hline GPA & 0.176 & 0.164 & 0.208 & 0.209 \\
& $(0.012)$ & $(0.011)$ & $(0.014)$ & $(0.013)$
\end{tabular}

\section{Controls}

$X \quad X$

\begin{tabular}{|c|c|}
\hline Observations & 3,646 \\
\hline
\end{tabular}

Note: This table reports the effect of an increase in first-year GPA on graduation. Panel A considers NELS:88 and ELS:2002. The regressions are run separately in NELS:88 and ELS:2002. 1988 refers to NELS:88 and 2002 refers to ELS:2002. Student characteristics include indicators for parent education, parent income, race, and gender as well as the percentile of math test scores. Math test percentiles come from pre-collegiate assessment tests. Graduation rates controls for the graduation rate of a student's major and major fixed effects are fixed effects for a student's choice of major. Panel B uses data from Public Liberal Arts College and has robust standard errors in parentheses. Control variables include: age, sex, race, SAT math composite quartile, and SAT verbal composite quartile. 


\section{Table 6: GPA Differences}

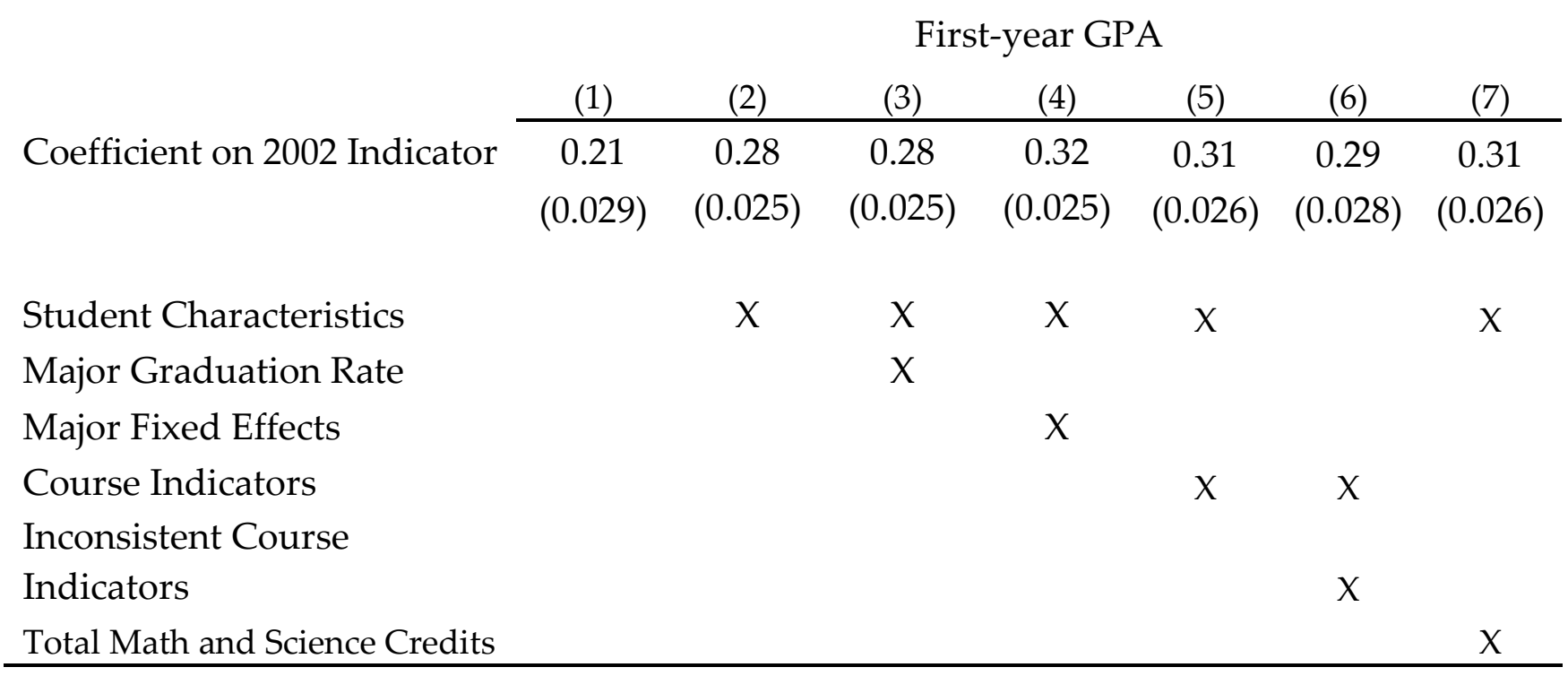

Notes: 1988 refers to NELS:88 and 2002 refers to ELS:2002. This table shows the coefficient on an indicator for an observation being 2002. Student characteristics include indicators for parent education, parent income, race, and gender as well as the percentile of math test scores. Math test percentiles come from pre-collegiate assessment tests. Graduation rates controls for the graduation rate of a student's major and major fixed effects are fixed effects for a student's choice of major. Course indicators include indicators for taking advanced calculus, physics, biology, chemistry, and Advanced Placement United States history. Inconsistent course indicators add controls for AP English Literature and Composition which did not appear in the 1988. Total Math and science credits controls for the total number of credits in Math and Science. 
Table 7: Changes in GPA Over Time, Large Public Universities

\begin{tabular}{cccccccc} 
& $(1)$ & $(2)$ & $(3)$ & $(4)$ & $(5)$ & $(6)$ & $(7)$ \\
\hline Year of Entry & 0.019 & 0.019 & 0.018 & 0.018 & 0.014 & 0.015 & 0.014 \\
& $(0.000)$ & $(0.000)$ & $(0.000)$ & $(0.000)$ & $(0.000)$ & $(0.000)$ & $(0.001)$
\end{tabular}

Student Characteristics

Home Zip Code Fixed Effects

\begin{tabular}{|c|c|c|c|c|}
\hline \multirow{5}{*}{\multicolumn{2}{|c|}{$\begin{array}{l}X \\
X\end{array}$}} & $X$ & $x$ & $X$ \\
\hline & & $x$ & $x$ & $X$ \\
\hline & & $X$ & $x$ & $X$ \\
\hline & & & $x$ & $X$ \\
\hline & & & & $X$ \\
\hline
\end{tabular}

University Fixed Effects

SAT Math and Verbal Fixed Effects

Major Fixed Effects

First-Semester Course Fixed Effects

$$
\begin{array}{llllllll}
\text { Observations } & 411,951 & 411,951 & 411,951 & 411,951 & 411,951 & 411,951 & 411,951
\end{array}
$$

Note: This table reports the time trend in first-year GPA from 1990 to 2000 at Clemson, Colorado, Colorado State, Florida, Florida State, Georgia Tech, North Carolina State, Purdue, and Virginia Tech. Student characteristics include age and indicators for race and ethnicity, gender, transfer student, and US citizenship. Home zip code fixed effects include a catch-all category for students without a reported US zip code. Indicators for each SAT math and SAT verbal score are interacted with indicators for the university. Institution-specific major fixed effects (defined at the end of the student's first year of college) and course fixed effects for every course in the student's first semester at the university are included in the final two specifications. Each observation is a unique student. 
Table 8: Changes in GPA Over Time, Public Liberal Arts

All Freshman Courses

Required

Science

Year of Entry

\begin{tabular}{cccccccc}
$(1)$ & $(2)$ & $(3)$ & $(4)$ & $(5)$ & $(6)$ & $(7)$ & $(8)$ \\
\hline 0.025 & 0.023 & 0.024 & 0.021 & 0.021 & 0.060 & 0.053 & 0.060 \\
$(0.001)$ & $(0.001)$ & $(0.001)$ & $(0.001)$ & $(0.001)$ & $(0.001)$ & $(0.002)$ & $(0.002)$
\end{tabular}

Course Fixed Effects

Student Characteristics

$X$

\begin{tabular}{|c|c|c|c|c|c|c|c|}
\hline \multirow{4}{*}{\multicolumn{2}{|c|}{$X$}} & $X$ & $X$ & $X$ & $X$ & $X$ & $X$ \\
\hline & & $X$ & $X$ & $X$ & $X$ & $X$ & $X$ \\
\hline & & & $X$ & $X$ & $X$ & $X$ & \\
\hline & & & & & & $X$ & $\begin{array}{l}X \\
X\end{array}$ \\
\hline 139,190 & 139,190 & 139,190 & 139,190 & 127,184 & 26,697 & 20,773 & 20,773 \\
\hline
\end{tabular}

$X$
$X$

\begin{tabular}{|c|c|c|c|c|c|c|c|}
\hline \multirow{4}{*}{\multicolumn{2}{|c|}{$X$}} & $X$ & $X$ & $X$ & $X$ & $X$ & $X$ \\
\hline & & $X$ & $X$ & $X$ & $X$ & $X$ & $X$ \\
\hline & & & $X$ & $X$ & $X$ & $X$ & \\
\hline & & & & & & $X$ & $\begin{array}{l}X \\
X\end{array}$ \\
\hline 139,190 & 139,190 & 139,190 & 139,190 & 127,184 & 26,697 & 20,773 & 20,773 \\
\hline
\end{tabular}

Exact Test Version Fixed Effect Test-Specific Final Exam Scores

Note: Observations are at the student-course level. Standard errors clustered at the student level. Samples in each column include students from $2001-$ 2012 enrolling cohorts. Freshmen take a required liberal arts curriculum that includes courses in Math, Science, Social Science, English, and History. Demographic variables include: age, sex, race, SAT math composite quartile, and SAT verbal composite quartile. Between 2001-2012, tests in two required science courses had similar structures, content, and point values year after year. In the first course, enrolling cohorts in 2002, 2007, 2009, 2010, and 2012 were given identical tests to the prior cohort. In the second course, enrolling cohorts in 2003, 2005, 2009, 2011, and 2012 were given identical tests to the prior cohort. Columns 1-4 include observations from all courses taken during freshman year. Column 5 includes student-course observations from all required freshman courses. Column 6 includes all student-course observations from a required science sequence. Columns 7-8 include estimates for students who took an identical test to at least one other cohort within the required science sequence. Column 7 controls for the exact test version students receive while column 8 controls for the interaction between test version and score-essentially creating a comparison of students with the same score on the same test. 
Table 9: Decomposition Exercise, Changes in College Graduation, BLT + First-Year Grades

\begin{tabular}{|c|c|c|c|c|c|c|c|}
\hline & $\begin{array}{c}\text { Full } \\
\text { Sample }\end{array}$ & $\begin{array}{c}\text { Public } \\
\text { non-top } \\
50\end{array}$ & $\begin{array}{l}\text { Public } \\
\text { top } 50\end{array}$ & $\begin{array}{c}\text { Private } \\
\text { Less } \\
\text { selective }\end{array}$ & $\begin{array}{l}\text { Private } \\
\text { Highly } \\
\text { Selective }\end{array}$ & $\begin{array}{l}\text { Community } \\
\text { College }\end{array}$ & $\begin{array}{c}\text { For-Profit } \\
\text { Schools }\end{array}$ \\
\hline NELS:88 & 48.73 & 56.12 & 82.15 & 72.26 & 90.50 & 19.56 & 25.15 \\
\hline ELS:2002 & 52.50 & 61.01 & 90.71 & 71.21 & 92.16 & 24.33 & 24.73 \\
\hline Total Change & 3.77 & 4.89 & 8.57 & -1.05 & 1.66 & 4.77 & -0.42 \\
\hline Change due to Observables & 2.49 & 2.77 & 2.44 & 2.73 & 5.75 & 2.57 & 3.31 \\
\hline \multicolumn{8}{|l|}{ Change due to Student } \\
\hline Characteristics & -0.92 & -1.65 & -0.85 & -0.01 & 2.27 & -0.41 & 7.13 \\
\hline $\begin{array}{l}\text { Math Test Percentile } \\
\text { Other Student }\end{array}$ & -0.75 & -1.12 & 0.08 & -0.30 & 0.06 & -0.65 & 0.32 \\
\hline Characteristics & -0.17 & -0.53 & -0.93 & 0.29 & 2.21 & 0.24 & 6.81 \\
\hline Change due to Supply-Side Factors & -0.16 & -1.68 & 0.00 & 0.00 & 0.69 & 0.09 & -0.13 \\
\hline Student/Faculty Ratios & -0.20 & -1.68 & 0.00 & 0.00 & 0.69 & 0.09 & -0.13 \\
\hline Initial School Types & 0.04 & & & & & & \\
\hline Change due to GPA & 3.57 & 6.09 & 3.29 & 2.74 & 2.78 & 2.89 & -3.69 \\
\hline Residual & 1.27 & 2.13 & 6.13 & -3.78 & -4.08 & 2.20 & -3.73 \\
\hline
\end{tabular}

Notes: These differences were found in the same way as the differences in Table 4, but adding another counterfactual ELS:2002 graduation rate using the NELS:88 distribution for GPA and using all other ELS:2002 observables. Furthermore, the change due to other characteristics is found by subtracting change due to GPA and change due to supply-side factors from change due to observables. 


\section{Appendix}

\section{Figure A1: College Enrollment over Time}

A. College Enrollment Rates, Recent High School Completers

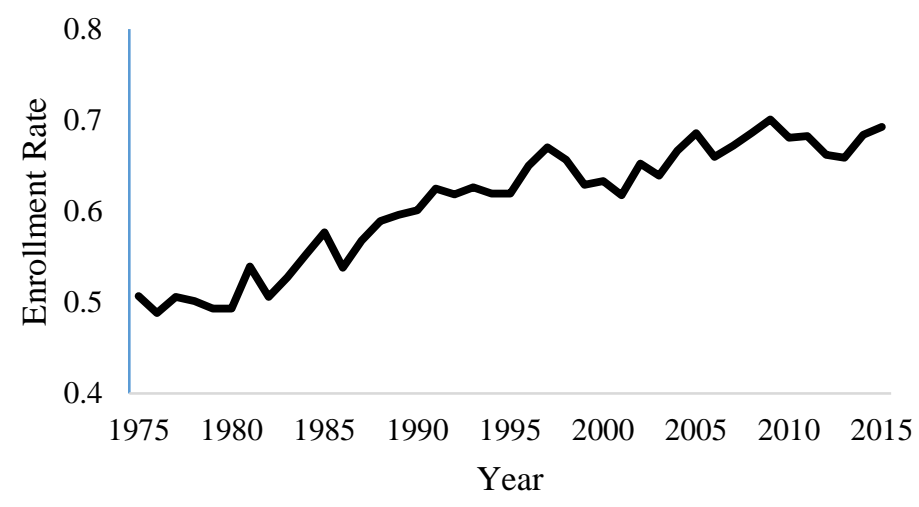

B. Total Number of Enrollees by Sector

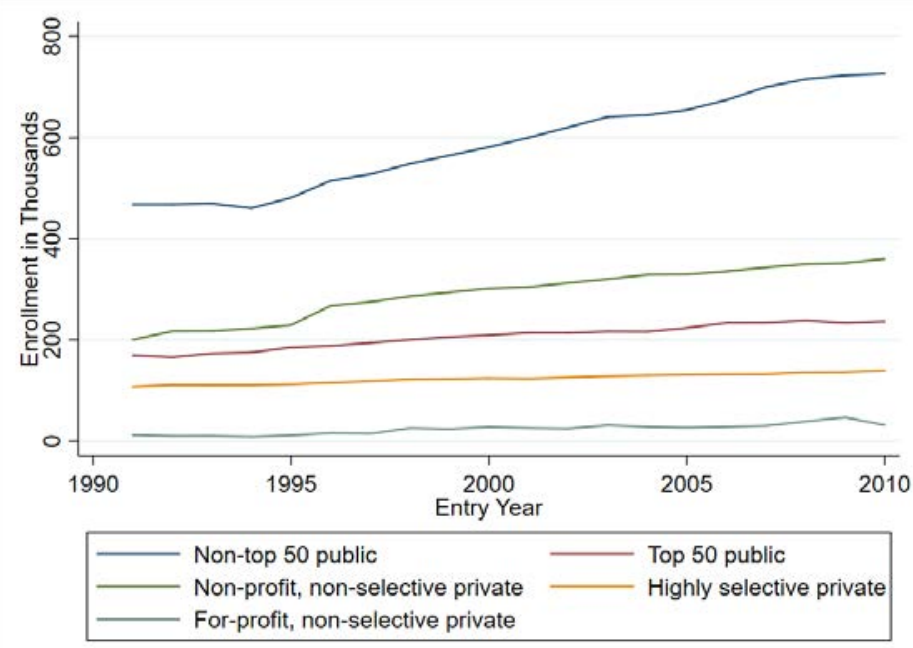

Note: In Panel A data come from NCES Digest of Education Statistics Table 302.30 (National Center for Education Statistics 2018). Panel A shows the fraction of individuals age 16-24 enrolled in college as of October who recently graduated from high school or completed a GED. Enrollment is defined as enrollment in college as of October. Source: U.S. Department of Commerce, Census Bureau, Current Population Survey (CPS), October, 1975 through 2015. Panel B Source: IPEDS. Panel B plots the total number of students enrolled by institution type. It shows the average sixyear graduation rate for different institution types. Cohort enrollment year refers to the year that students were first enrolled. See Section 4 in the text for a detailed description of how institutions are assigned to a type. Schools that were predominantly online are excluded for all cohorts. These totals were calculated only using students who were first-time, full-time degree seeking students in their respective entry years. 
Figure A2: Non-linear Relationship between GPA and graduation, Large Public and Public Liberal Arts Samples

A. Large Public, Early

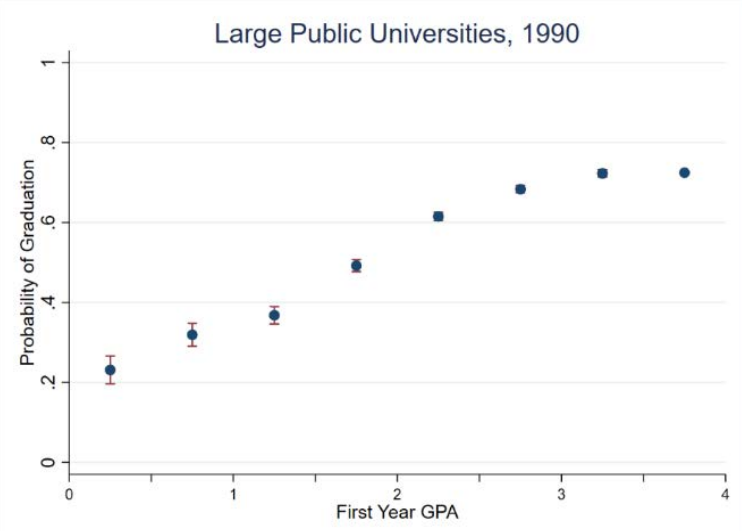

C. Public Liberal Arts, Early

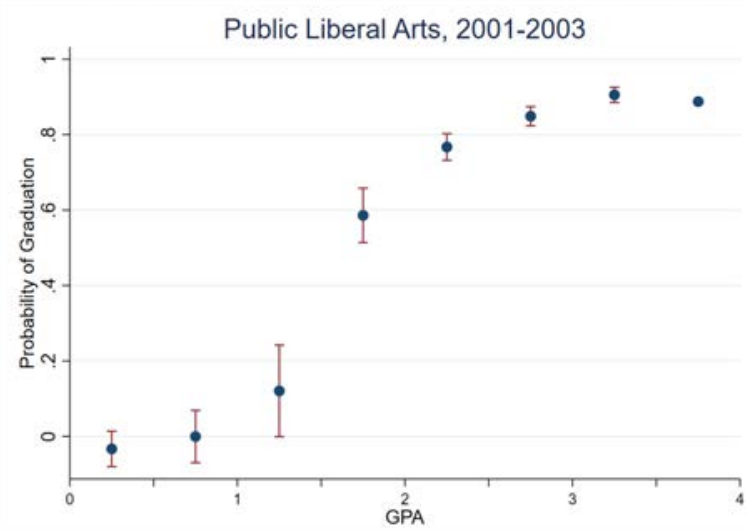

B. Large Public, Late

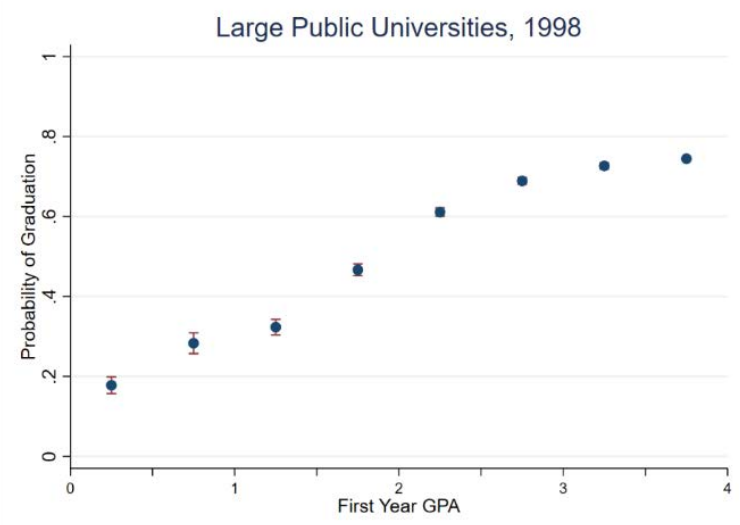

D. Public Liberal Arts, Late

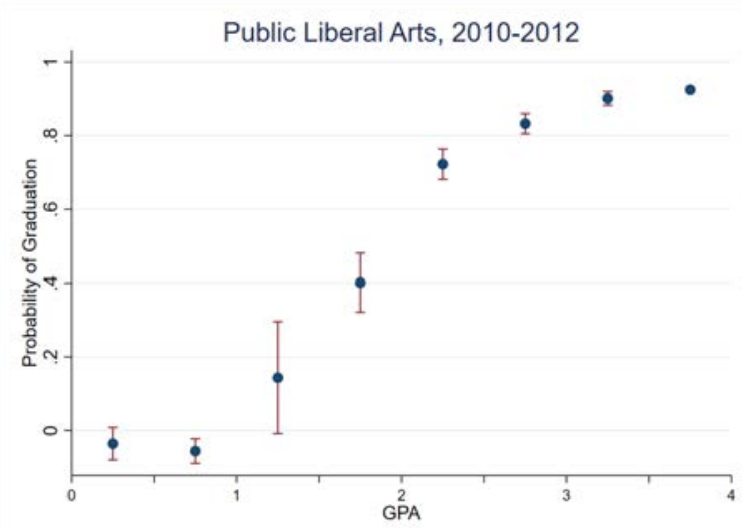

Notes: Panels $A$ and $B$ shows the relationship between GPA and graduation at the sample of Large Public Universities which includes: Clemson, Colorado, Colorado State, Florida, Florida State, Georgia Tech, North Carolina State, Purdue, and Virginia Tech. Each point in Panels A and B represents the coefficient on an indicator for a GPA range $(0$ to $.5, .5$ to $1, \ldots)$ relative to students in the top GPA bin in a regression that includes controls for student SAT math score fixed effects as well as indicators for student race, gender, and transfer student status. The top bin is calculated from the same regression without controls. Panels $C$ and $D$ show the relationship between GPA and graduation at the Public Liberal Arts College. Each point in Panels $C$ and D represents the coefficient on an indicator for GPA window (0 to .5, .5 to 1, ..) relative to students in the top GPA bin in a regression that includes controls for age, race, sex, and quartiles of SAT math and verbal scores. The top bin is calculated using the constant from the same regression without controls. 
Figure A3: Cumulative Distribution of First-Year GPA, Large Public Universities

A. $1990 \& 2000$

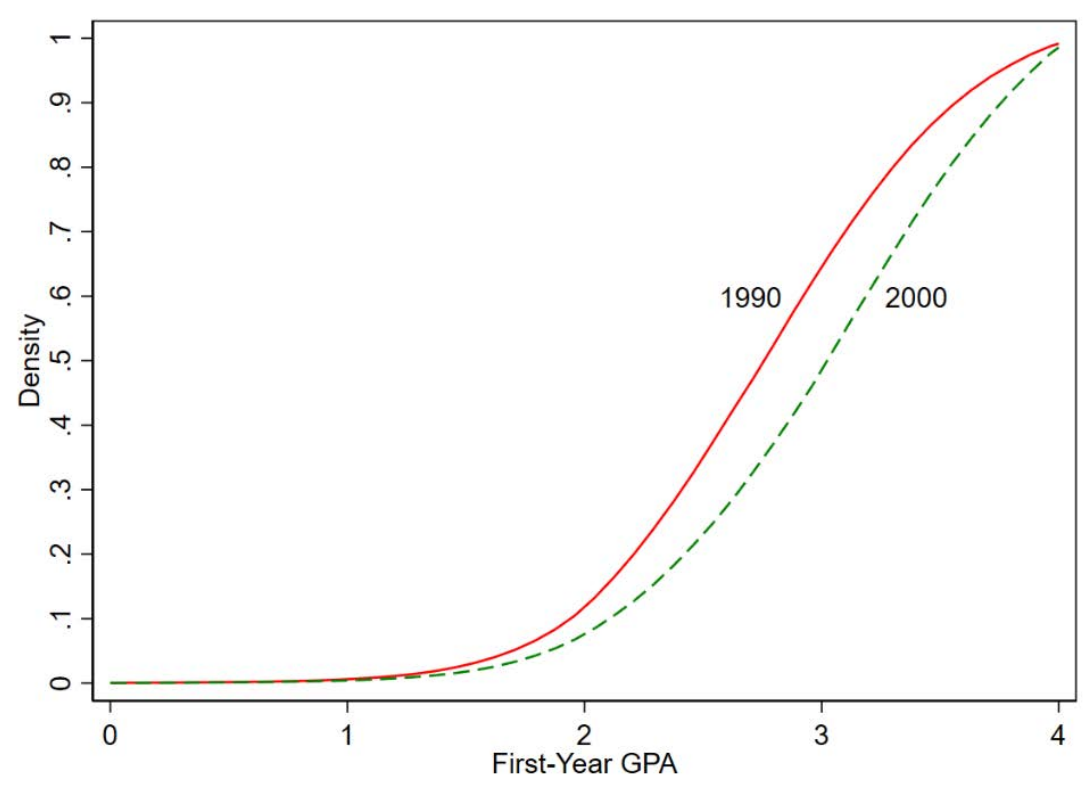

B. $2009 \& 2014$

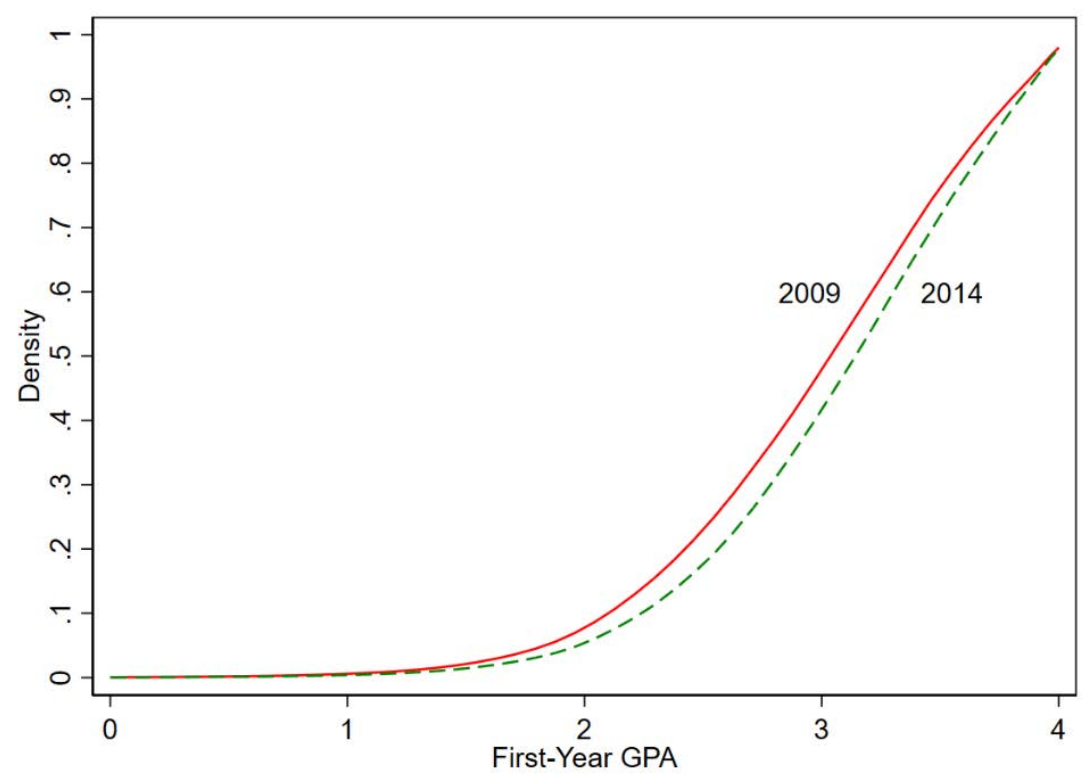

Notes: This plots a smoothed CDF of first-year GPA for the entering cohort of the given year. Panel A includes: Clemson, Colorado, Colorado State, Florida, Florida State, Georgia Tech, North Carolina State, Purdue, and Viginia Tech. Panel B includes: Colorado, Colorado State, North Carolina State, North Carolina - Charlotte, Oklahoma, Purdue, South Dakota School of Mines, and Utah State. 
Figure A4:

CDF Distribution of GPA- Public Liberal Arts

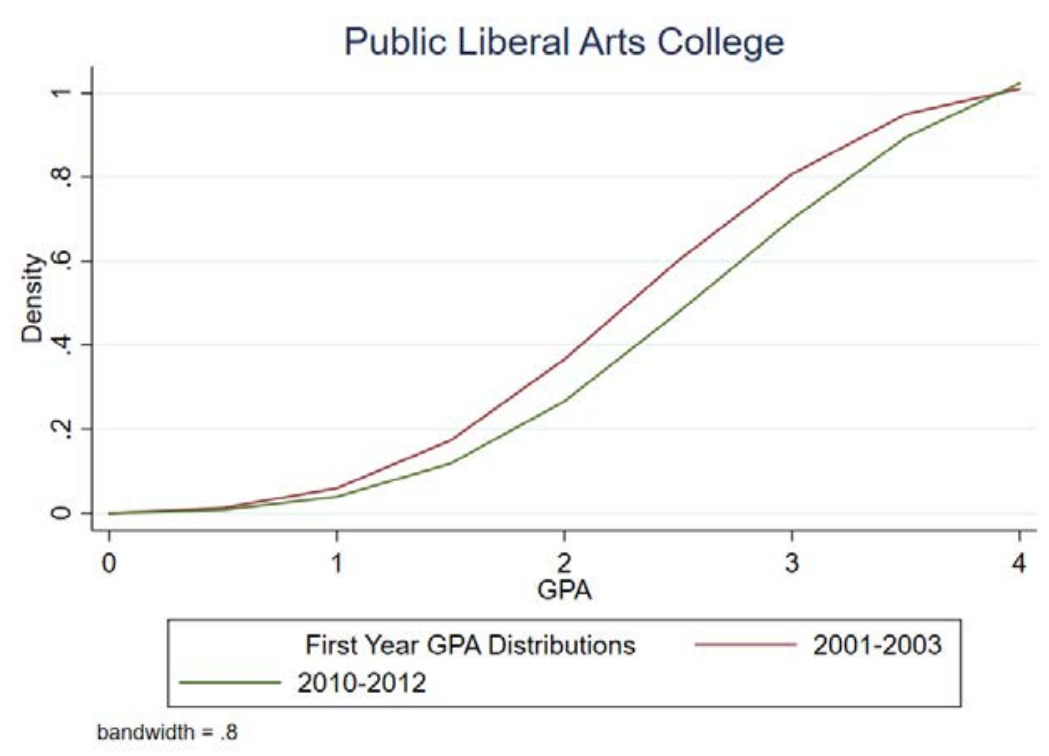

Notes: Figure A4 plots smoothed cdfs offirst-year GPA. 
Table A1: Summary Statistics, Large Public Universities

\begin{tabular}{lllll}
\hline & \multicolumn{2}{l}{ All Students } & \multicolumn{2}{l}{ BA Recipients } \\
Variable & 1990 & 2000 & 1990 & 2000 \\
\hline Bottom SAT Math Quartile & 0.05 & 0.05 & 0.04 & 0.04 \\
Second SAT Math Quartile & 0.20 & 0.19 & 0.19 & 0.17 \\
Third SAT Math Quartile & 0.41 & 0.35 & 0.41 & 0.35 \\
Top SAT Math Quartile & 0.34 & 0.40 & 0.39 & 0.43 \\
SAT Math & 574.5 & 582.0 & 580.8 & 589.7 \\
\hline Six-Year Graduation & 0.62 & 0.64 & 1.00 & 1.00 \\
GPA & 2.68 & 2.79 & 2.85 & 2.99 \\
Transfer Student & 0.15 & 0.15 & 0.17 & 0.16 \\
Major Graduation Rate & 0.61 & 0.61 & 0.70 & 0.69 \\
\hline Race/Ethnicity: & & & & \\
$\quad$ Asian & 0.04 & 0.05 & 0.04 & 0.05 \\
$\quad$ Hispanic & 0.03 & 0.05 & 0.03 & 0.05 \\
$\quad$ African American & 0.06 & 0.06 & 0.05 & 0.06 \\
$\quad 0.79$ & 0.78 & 0.80 & 0.79 \\
\hline Male & 0.55 & 0.53 & 0.54 & 0.52 \\
\hline Number of Observations & 32,417 & 41,414 & 19,998 & 26,398 \\
\hline
\end{tabular}

Note: This table presents summary statistics from degree-seeking enrolled students at Clemson, Colorado, Colorado State, Florida, Florida State, Georgia Tech, North Carolina State, Purdue, and Virginia Tech. Each observation is a unique student. Students with no reported SAT or ACT score (nearly all are transfer students) are excluded. 
Table A2: Summary Statistics, Public Liberal Arts

\begin{tabular}{llcc} 
Variable & 2001-2003 & 2010-2012 \\
\hline Bottom SAT Math Quartile & 554 & 549 \\
Second SAT Math Quartile & 621 & 621 \\
Third SAT Math Quartile & 669 & 669 \\
Top SAT Math Quartile & 732 & 737 \\
SAT Math & 638 & 642 \\
\hline Six-Year Graduation & & 0.831 & 0.859 \\
GPA & 2.773 & 3.023 \\
\hline Race/Ethnicity: & & \\
& Asian & 0.066 & 0.069 \\
& Hispanic & 0.075 & 0.094 \\
& African & 0.065 & 0.095 \\
& American & & \\
& White & 0.764 & 0.707 \\
\hline Number of Observations & & 3,367 & 3,646 \\
\hline
\end{tabular}

Note: This table presents summary statistics for students in the 2001-2003 and 2010-2012 enrolling cohorts from a public liberal arts college. 
Table A3: College Resources

Panel A: Full Sample

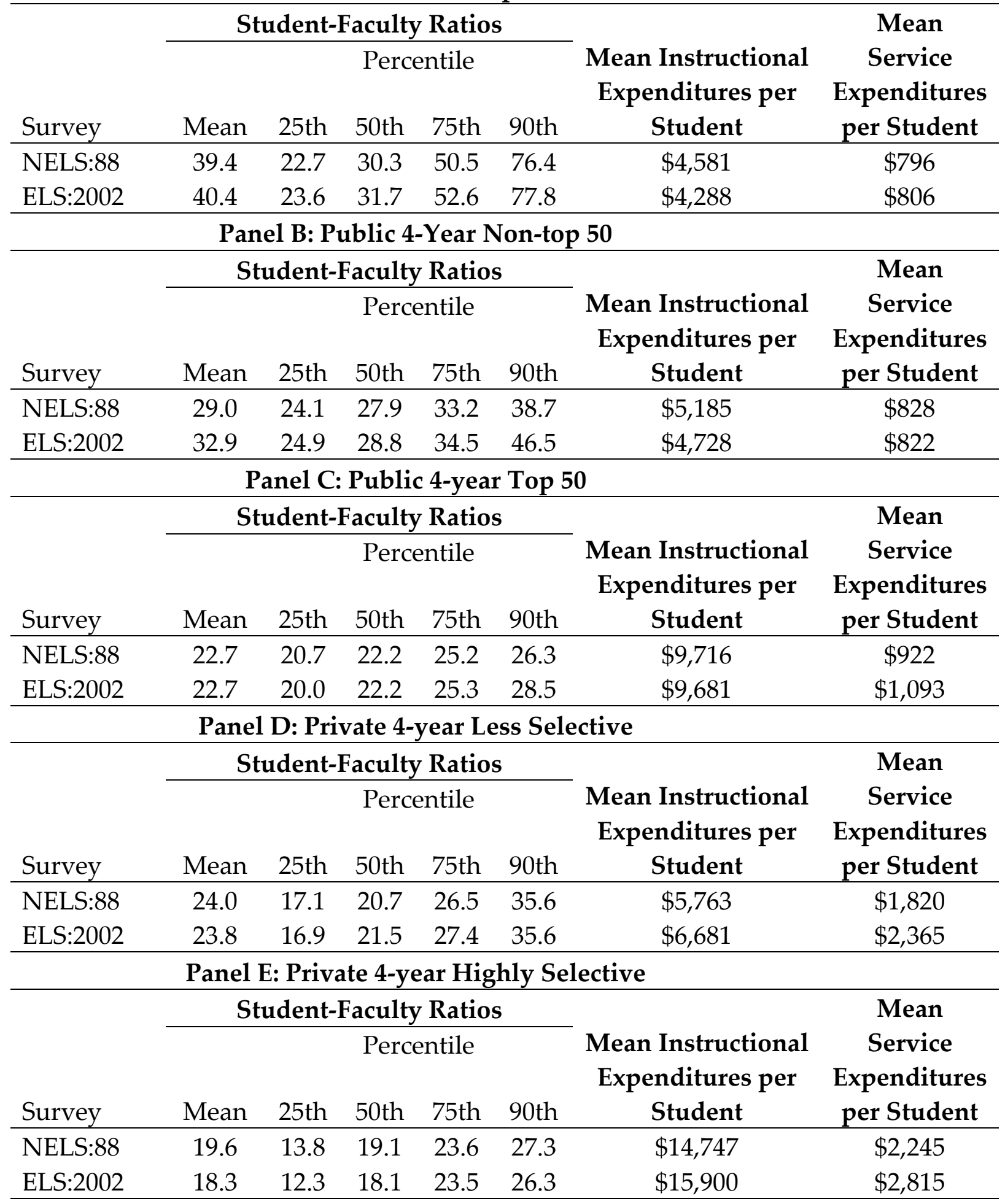

Panel F: 2-Year 


\begin{tabular}{|c|c|c|c|c|c|c|c|}
\hline \multirow[b]{3}{*}{ Survey } & \multicolumn{5}{|c|}{ Student-Faculty Ratios } & \multirow{3}{*}{$\begin{array}{l}\text { Mean Instructional } \\
\text { Expenditures per } \\
\text { Student }\end{array}$} & \multirow{3}{*}{$\begin{array}{c}\text { Mean } \\
\text { Service } \\
\text { Expenditures } \\
\text { per Student }\end{array}$} \\
\hline & & & Perc & ntile & & & \\
\hline & Mean & 25th & 50th & 75th & 90th & & \\
\hline NELS:88 & 60.6 & 41.0 & 59.3 & 76.4 & 91.1 & $\$ 2,683$ & $\$ 552$ \\
\hline ELS:2002 & 61.0 & 43.5 & 59.4 & 76.3 & 90.1 & $\$ 2,467$ & $\$ 555$ \\
\hline \multicolumn{8}{|c|}{ Panel G: For-Profit } \\
\hline & \multicolumn{5}{|c|}{ Student-Faculty Ratios } & \multirow[b]{2}{*}{$\begin{array}{l}\text { Mean Instructional } \\
\text { Expenditures per } \\
\text { Student }\end{array}$} & \multirow{2}{*}{$\begin{array}{c}\text { Mean } \\
\text { Service } \\
\text { Expenditures } \\
\text { per Student }\end{array}$} \\
\hline Survey & Mean & 25th & Perc & ntile & 90th & & \\
\hline NELS:88 & 42.0 & 31.6 & 42.2 & 44.4 & 62.2 & $\$ 3,319$ & N/A \\
\hline ELS:2002 & 43.9 & 31.3 & 36.7 & 59.1 & 74.8 & $\$ 3,417$ & N/A \\
\hline
\end{tabular}

Note: This table describes the school resources by college type in the NELS:88 and ELS:2002. 
Table A4: Predicting College Graduation

Panel A: ELS:2002

\begin{tabular}{|c|c|c|c|c|c|c|}
\hline & $\begin{array}{c}\text { Full } \\
\text { Sample }\end{array}$ & $\begin{array}{c}\text { Public } \\
\text { non-top } \\
50\end{array}$ & $\begin{array}{l}\text { Public } \\
\text { top } 50\end{array}$ & $\begin{array}{l}\text { Private } \\
\text { less } \\
\text { selective }\end{array}$ & $\begin{array}{l}\text { Private } \\
\text { highly } \\
\text { selective }\end{array}$ & $\begin{array}{c}\text { Community } \\
\text { College }\end{array}$ \\
\hline First-Year College GPA & $\begin{array}{l}1.081 \\
(0.06)\end{array}$ & $\begin{array}{l}1.255 \\
(0.09)\end{array}$ & $\begin{array}{l}1.435 \\
(0.27)\end{array}$ & $\begin{array}{l}1.441 \\
(0.17)\end{array}$ & $\begin{array}{l}1.813 \\
(0.43)\end{array}$ & $\begin{array}{l}0.801 \\
(0.08)\end{array}$ \\
\hline Ln(student/faculty) & $\begin{array}{l}-0.390 \\
(0.12)\end{array}$ & $\begin{array}{l}-1.122 \\
(0.21)\end{array}$ & $\begin{array}{l}0.026 \\
(0.93)\end{array}$ & $\begin{array}{l}-0.568 \\
(0.38)\end{array}$ & $\begin{array}{l}-1.776 \\
(0.81)\end{array}$ & $\begin{array}{l}0.272 \\
(0.18)\end{array}$ \\
\hline Missing(student/faculty) & $\begin{array}{l}-3.008 \\
(0.78)\end{array}$ & $\begin{array}{r}-3.248 \\
(1.73)\end{array}$ & $\begin{array}{c}0.000 \\
(.)\end{array}$ & $\begin{array}{l}-3.365 \\
(1.73)\end{array}$ & $\begin{array}{c}0.000 \\
(.)\end{array}$ & $\begin{array}{l}-1.284 \\
(1.30)\end{array}$ \\
\hline Math percentile & $\begin{array}{l}0.016 \\
(0.00)\end{array}$ & $\begin{array}{l}0.014 \\
(0.00)\end{array}$ & $\begin{array}{l}0.020 \\
(0.01)\end{array}$ & $\begin{array}{l}0.012 \\
(0.00)\end{array}$ & $\begin{array}{l}0.004 \\
(0.01)\end{array}$ & $\begin{array}{l}0.017 \\
(0.00)\end{array}$ \\
\hline $\begin{array}{l}\text { Missing(student/faculty)x(math } \\
\text { percentile) }\end{array}$ & $\begin{array}{l}0.027 \\
(0.01)\end{array}$ & $\begin{array}{l}0.007 \\
(0.04)\end{array}$ & $\begin{array}{c}0.000 \\
(.)\end{array}$ & $\begin{array}{r}-0.001 \\
(0.02)\end{array}$ & $\begin{array}{c}0.000 \\
(.)\end{array}$ & $\begin{array}{l}0.047 \\
(0.02)\end{array}$ \\
\hline Income $20,000 / 25,000$ & $\begin{array}{l}0.102 \\
(0.18)\end{array}$ & $\begin{array}{l}0.146 \\
(0.31)\end{array}$ & $\begin{array}{l}-1.444 \\
(0.79)\end{array}$ & $\begin{array}{l}-0.621 \\
(0.58)\end{array}$ & $\begin{array}{l}0.309 \\
(1.76)\end{array}$ & $\begin{array}{l}0.410 \\
(0.29)\end{array}$ \\
\hline Income $25,000 / 35,000$ & $\begin{array}{l}-0.293 \\
(0.18)\end{array}$ & $\begin{array}{l}-0.231 \\
(0.30)\end{array}$ & $\begin{array}{l}-1.139 \\
(0.75)\end{array}$ & $\begin{array}{l}-0.725 \\
(0.55)\end{array}$ & $\begin{array}{l}1.199 \\
(0.96)\end{array}$ & $\begin{array}{l}-0.232 \\
(0.32)\end{array}$ \\
\hline Income $35,000 / 50,000$ & $\begin{array}{l}0.034 \\
(0.17)\end{array}$ & $\begin{array}{l}-0.022 \\
(0.28)\end{array}$ & $\begin{array}{l}-0.796 \\
(0.60)\end{array}$ & $\begin{array}{r}-0.569 \\
(0.52)\end{array}$ & $\begin{array}{l}0.961 \\
(1.00)\end{array}$ & $\begin{array}{l}0.304 \\
(0.28)\end{array}$ \\
\hline Income 50,000/75,000 & $\begin{array}{l}0.112 \\
(0.17)\end{array}$ & $\begin{array}{l}0.091 \\
(0.28)\end{array}$ & $\begin{array}{l}-0.893 \\
(0.77)\end{array}$ & $\begin{array}{l}-0.929 \\
(0.53)\end{array}$ & $\begin{array}{l}0.229 \\
(0.65)\end{array}$ & $\begin{array}{l}0.501 \\
(0.28)\end{array}$ \\
\hline Income 50,000+/75,000+ & $\begin{array}{l}0.443 \\
(0.17)\end{array}$ & $\begin{array}{l}0.487 \\
(0.27)\end{array}$ & $\begin{array}{l}-0.495 \\
(0.71)\end{array}$ & $\begin{array}{c}-0.096 \\
(0.53)\end{array}$ & $\begin{array}{l}\text { N/A } \\
\text { N/A }\end{array}$ & $\begin{array}{l}0.599 \\
(0.28)\end{array}$ \\
\hline Father HS diploma & -0.015 & 0.064 & 0.138 & -0.179 & 2.014 & -0.088 \\
\hline
\end{tabular}




\begin{tabular}{|c|c|c|c|c|c|c|}
\hline & $(0.16)$ & $(0.27)$ & $(1.05)$ & $(0.47)$ & $(2.25)$ & $(0.29)$ \\
\hline \multirow[t]{2}{*}{ Father some college } & 0.134 & 0.045 & 0.533 & 0.402 & 1.798 & 0.054 \\
\hline & $(0.16)$ & $(0.29)$ & $(1.09)$ & $(0.47)$ & $(2.70)$ & $(0.26)$ \\
\hline \multirow[t]{2}{*}{ Father BA } & 0.340 & 0.410 & 0.987 & 0.211 & 2.839 & 0.194 \\
\hline & $(0.18)$ & $(0.27)$ & $(1.20)$ & $(0.53)$ & $(2.42)$ & $(0.29)$ \\
\hline \multirow[t]{2}{*}{ Father graduate school } & 0.437 & 0.264 & 1.258 & 0.475 & 2.814 & 0.388 \\
\hline & $(0.18)$ & $(0.32)$ & $(1.19)$ & $(0.55)$ & $(2.45)$ & $(0.28)$ \\
\hline \multirow[t]{2}{*}{ Mother HS diploma } & 0.225 & 0.051 & -0.081 & 0.989 & -0.669 & 0.202 \\
\hline & $(0.17)$ & $(0.28)$ & $(0.86)$ & $(0.50)$ & $(2.36)$ & $(0.27)$ \\
\hline \multirow[t]{2}{*}{ Mother some college } & 0.376 & 0.190 & -0.525 & 0.854 & -0.206 & 0.502 \\
\hline & $(0.16)$ & $(0.27)$ & $(0.84)$ & $(0.53)$ & $(2.10)$ & $(0.25)$ \\
\hline \multirow[t]{2}{*}{ Mother BA } & 0.459 & 0.180 & -0.708 & 1.484 & -0.997 & 0.602 \\
\hline & $(0.18)$ & $(0.29)$ & $(1.06)$ & $(0.54)$ & $(2.11)$ & $(0.29)$ \\
\hline \multirow[t]{2}{*}{ Mother graduate school } & 0.380 & 0.180 & -1.384 & 1.411 & -0.160 & 0.406 \\
\hline & $(0.19)$ & $(0.29)$ & $(1.00)$ & $(0.54)$ & $(2.23)$ & $(0.31)$ \\
\hline \multirow[t]{2}{*}{ Asian } & 0.633 & 0.713 & -0.192 & 0.337 & 0.648 & 0.642 \\
\hline & $(0.13)$ & $(0.19)$ & $(0.35)$ & $(0.42)$ & $(1.02)$ & $(0.20)$ \\
\hline \multirow[t]{2}{*}{ Hispanic } & -0.023 & 0.004 & 1.017 & -0.043 & 1.511 & -0.224 \\
\hline & $(0.12)$ & $(0.21)$ & $(0.81)$ & $(0.36)$ & $(1.37)$ & $(0.17)$ \\
\hline \multirow[t]{2}{*}{ Black } & 0.026 & -0.033 & 1.508 & -0.548 & -1.668 & 0.162 \\
\hline & $(0.12)$ & $(0.18)$ & $(0.49)$ & $(0.31)$ & $(0.81)$ & $(0.22)$ \\
\hline \multirow[t]{2}{*}{ Male } & -0.242 & -0.122 & -0.519 & -0.341 & -0.222 & -0.250 \\
\hline & $(0.08)$ & $(0.13)$ & $(0.46)$ & $(0.25)$ & $(0.48)$ & $(0.12)$ \\
\hline \multirow[t]{2}{*}{ Public top 50} & 1.138 & & & & & \\
\hline & $(0.20)$ & & & & & \\
\hline \multirow[t]{2}{*}{ Private less selective } & 0.089 & & & & & \\
\hline & $(0.13)$ & & & & & \\
\hline Private highly selective & 0.846 & & & & & \\
\hline
\end{tabular}




\begin{tabular}{lcccccc} 
Community college & $(0.25)$ & & & & & \\
& -1.223 & & & & & \\
For-profit & $(0.12)$ & & & & & \\
& -1.039 & & & & & \\
Income $<20,000 /<25,000$ & $(0.27)$ & & & & & N/A \\
& $\mathrm{N} / \mathrm{A}$ & $\mathrm{N} / \mathrm{A}$ & $\mathrm{N} / \mathrm{A}$ & $\mathrm{N} / \mathrm{A}$ & 0.000 & $\mathrm{~N} / \mathrm{A}$ \\
Constant & $\mathrm{N} / \mathrm{A}$ & $\mathrm{N} / \mathrm{A}$ & $\mathrm{N} / \mathrm{A}$ & $\mathrm{N} / \mathrm{A}$ & $()$. & -5.811 \\
& -2.488 & -0.208 & -2.177 & -2.467 & 0.356 & $(0.80)$ \\
\hline
\end{tabular}

First-Year College GPA

Ln(student/faculty)

Missing(student/faculty)

Math percentile

Missing(student/faculty)x(math percentile)

Income 20,000/25,000

Income 25,000/35,000
Panel B: NELS:88

\section{Public Private Private}

Full non- Public less highly Community

\begin{tabular}{cccccc} 
Sample & top 50 & top 50 & selective & selective & College \\
\hline 1.344 & 1.734 & 1.887 & 1.365 & 1.657 & 1.044
\end{tabular}

$\begin{array}{llllll}(0.08) & (0.14) & (0.27) & (0.18) & (0.41) & (0.11)\end{array}$

$\begin{array}{llllll}-0.571 & -1.616 & -1.962 & -0.799 & -0.151 & -0.340\end{array}$

$\begin{array}{llllll}(0.15) & (0.42) & (0.96) & (0.25) & (0.58) & (0.20)\end{array}$

$\begin{array}{llllll}-3.957 & -21.465 & 0.000 & -5.787 & 0.000 & -0.942\end{array}$

$\begin{array}{llllll}(1.06) & (9.44) & (.) & (2.16) & (.) & (1.20)\end{array}$

$\begin{array}{llllll}0.013 & 0.005 & 0.019 & 0.010 & 0.004 & 0.020\end{array}$

$\begin{array}{llllll}(0.00) & (0.00) & (0.01) & (0.01) & (0.01) & (0.00)\end{array}$

$\begin{array}{llllll}0.010 & 0.184 & 0.000 & 0.046 & 0.000 & -0.039\end{array}$

$\begin{array}{llllll}(0.01) & (0.12) & (.) & (0.03) & (.) & (0.02)\end{array}$

$\begin{array}{llllll}0.025 & 0.418 & -0.536 & -0.500 & -0.904 & -0.099\end{array}$

$\begin{array}{llllll}(0.26) & (0.41) & (1.10) & (0.64) & (0.98) & (0.49)\end{array}$

$\begin{array}{llllll}0.295 & 0.242 & -0.552 & -0.281 & -0.921 & 0.686\end{array}$ 


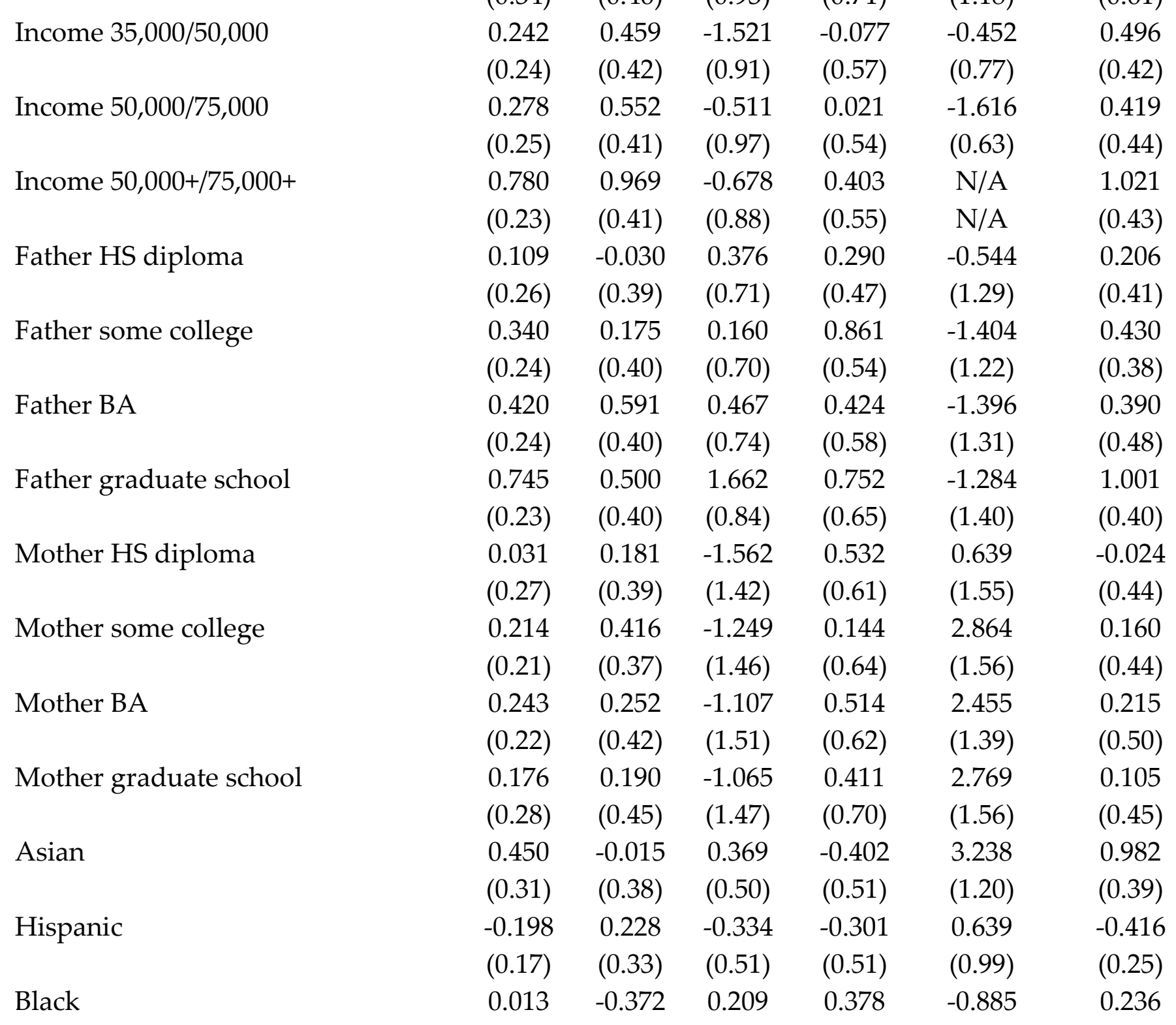




\begin{tabular}{lcccccc} 
& $(0.22)$ & $(0.29)$ & $(0.46)$ & $(0.36)$ & $(1.01)$ & $(0.46)$ \\
Male & -0.288 & -0.501 & -0.648 & 0.062 & 0.059 & -0.199 \\
& $(0.10)$ & $(0.16)$ & $(0.30)$ & $(0.22)$ & $(0.53)$ & $(0.16)$ \\
Public top 50 & 0.758 & & & & & \\
Private less selective & $(0.15)$ & & & & & \\
& 0.318 & & & & & \\
Private highly selective & $(0.15)$ & & & & & \\
& 0.869 & & & & & \\
Community college & $(0.30)$ & & & & & \\
& -1.202 & & & & & \\
For-profit & $(0.17)$ & & & & & \\
& -1.008 & & & & & N/A \\
Income $<20,000 /<25,000$ & $(0.56)$ & & & & & \\
& N/A & N/A & N/A & N/A & 1.593 & N/A \\
Constant & N/A & N/A & N/A & N/A & $(1.44)$ & \\
& -2.596 & 0.403 & 3.463 & -1.685 & -2.574 & -4.553 \\
\hline
\end{tabular}

Notes: This reports the coefficients on various predictors of college graduation for the entire sample and separately by school type. Panel A shows ELS:2002 and Panel B shows NELS:88. 
Table A5: Relationship between Graduation and GPA, Large Public Universities Sample

\begin{tabular}{|c|c|c|c|c|c|c|c|}
\hline & $(1)$ & $(2)$ & (3) & $(4)$ & (5) & (6) & (7) \\
\hline \multirow[t]{2}{*}{ First-Year GPA } & 0.22 & 0.22 & 0.21 & 0.21 & 0.21 & 0.19 & 0.18 \\
\hline & $(0.00)$ & $(0.00)$ & $(0.00)$ & $(0.00)$ & $(0.00)$ & $(0.00)$ & $(0.00)$ \\
\hline \multirow[t]{2}{*}{ GPA x 1991} & -0.01 & -0.01 & 0.00 & -0.00 & -0.00 & -0.00 & 0.00 \\
\hline & $(0.00)$ & $(0.00)$ & $(0.00)$ & $(0.00)$ & $(0.00)$ & $(0.00)$ & $(0.00)$ \\
\hline \multirow[t]{2}{*}{ GPA x 1992} & -0.00 & -0.00 & 0.00 & 0.00 & 0.00 & 0.00 & 0.01 \\
\hline & $(0.00)$ & $(0.00)$ & $(0.00)$ & $(0.00)$ & $(0.00)$ & $(0.00)$ & $(0.00)$ \\
\hline \multirow[t]{2}{*}{ GPA $\times 1993$} & -0.00 & -0.00 & 0.00 & -0.00 & 0.00 & 0.00 & 0.01 \\
\hline & $(0.00)$ & $(0.00)$ & $(0.00)$ & $(0.00)$ & $(0.00)$ & $(0.00)$ & $(0.00)$ \\
\hline \multirow[t]{2}{*}{ GPA x 1994} & -0.01 & -0.01 & -0.00 & -0.00 & -0.00 & 0.00 & 0.00 \\
\hline & $(0.00)$ & $(0.00)$ & $(0.00)$ & $(0.00)$ & $(0.00)$ & $(0.00)$ & $(0.00)$ \\
\hline \multirow[t]{2}{*}{ GPA x 1995} & -0.00 & -0.01 & -0.00 & -0.00 & -0.00 & 0.00 & 0.00 \\
\hline & $(0.00)$ & $(0.00)$ & $(0.00)$ & $(0.00)$ & $(0.00)$ & $(0.00)$ & $(0.00)$ \\
\hline \multirow[t]{2}{*}{ GPA x 1996} & -0.00 & -0.01 & 0.00 & 0.00 & -0.00 & 0.00 & 0.01 \\
\hline & $(0.00)$ & $(0.00)$ & $(0.00)$ & $(0.00)$ & $(0.00)$ & $(0.00)$ & $(0.00)$ \\
\hline \multirow[t]{2}{*}{ GPA x 1997} & 0.00 & -0.00 & 0.00 & 0.00 & 0.00 & 0.00 & 0.01 \\
\hline & $(0.00)$ & $(0.00)$ & $(0.00)$ & $(0.00)$ & $(0.00)$ & $(0.00)$ & $(0.00)$ \\
\hline \multirow[t]{2}{*}{ GPA x 1998} & -0.00 & -0.00 & -0.00 & -0.00 & -0.00 & 0.00 & 0.01 \\
\hline & $(0.00)$ & $(0.00)$ & $(0.00)$ & $(0.00)$ & $(0.00)$ & $(0.00)$ & $(0.00)$ \\
\hline \multicolumn{2}{|c|}{ Student Characteristics } & $X$ & $X$ & $X$ & $X$ & $X$ & $X$ \\
\hline \multicolumn{2}{|c|}{ Home Zip Code Fixed Effects } & & $X$ & $X$ & $X$ & $X$ & $X$ \\
\hline \multicolumn{2}{|c|}{ University Fixed Effects } & & & $X$ & $X$ & $X$ & $X$ \\
\hline \multicolumn{3}{|c|}{ SAT Math and Verbal Fixed Effects } & & & $X$ & $X$ & $X$ \\
\hline \multicolumn{3}{|c|}{ Major Fixed Effects } & & & & $X$ & $X$ \\
\hline
\end{tabular}




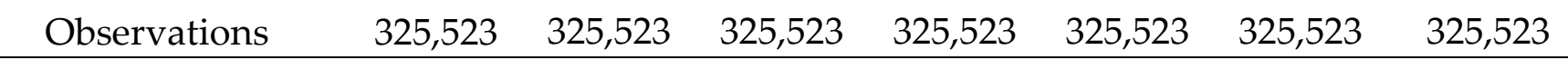

Note: This table reports the effect of an increase in first-year GPA on graduation for the entering cohorts from 1990 to 1998 at Clemson, Colorado, Colorado State, Florida, Florida State, Georgia Tech, North Carolina State, Purdue, and Virginia Tech. An interaction between first-year GPA and entering cohort year is included for each year. Student characteristics include age and indicators for race and ethnicity, gender, transfer student, and US citizenship. Home zip code fixed effects include a catch-all category for students without a reported US zip code. Indicators for each SAT math and SAT verbal score are interacted with indicators for the university. Institution-specific major fixed effects (defined at the end of the student's first year of college) and course fixed effects for every course in the student's first semester at the university are included in the final two specifications. Each observation is a unique student. 
Table A6: Decomposition Exercise, Changes in College Graduation, BLT + First-Year Grades

\begin{tabular}{|c|c|c|c|c|c|c|c|}
\hline & $\begin{array}{c}\text { Full } \\
\text { Sample }\end{array}$ & $\begin{array}{c}\text { Public } \\
\text { non-top } \\
50\end{array}$ & $\begin{array}{l}\text { Public } \\
\text { top } 50\end{array}$ & $\begin{array}{c}\text { Private } \\
\text { Less } \\
\text { selective }\end{array}$ & $\begin{array}{c}\text { Private } \\
\text { Highly } \\
\text { Selective }\end{array}$ & $\begin{array}{c}\text { Community } \\
\text { College }\end{array}$ & $\begin{array}{c}\text { For-Profit } \\
\text { Schools }\end{array}$ \\
\hline NELS:88 & 48.73 & 56.12 & 82.15 & 72.26 & 90.50 & 19.56 & 25.15 \\
\hline ELS:2002 & 52.50 & 61.01 & 90.71 & 71.21 & 92.16 & 24.33 & 24.73 \\
\hline Total Change & 3.77 & 4.89 & 8.57 & -1.05 & 1.66 & 4.77 & -0.42 \\
\hline Change due to Observables & 2.22 & 2.60 & 0.63 & 1.64 & 3.45 & 2.54 & 3.78 \\
\hline Change due to Student Characteristics & -0.98 & -1.64 & -0.94 & 0.19 & 3.62 & -0.23 & 15.94 \\
\hline Math Test Percentile & -0.79 & -1.18 & 0.05 & -0.53 & -1.04 & -0.65 & -5.77 \\
\hline Other Student Characteristics & -0.19 & -0.45 & -0.99 & 0.73 & 4.66 & 0.42 & 21.71 \\
\hline Change due to Supply-Side Factors & -0.17 & -1.61 & -0.02 & -0.14 & -0.48 & 0.10 & -6.72 \\
\hline Student/Faculty Ratios & -0.19 & -1.61 & -0.02 & -0.14 & -0.48 & 0.10 & -6.72 \\
\hline Initial School Types & 0.03 & & & & & & \\
\hline Change due to Nonlinear GPA & 3.37 & 5.85 & 1.59 & 1.58 & 0.31 & 2.67 & -5.44 \\
\hline Residual & 1.54 & 2.29 & 7.94 & -2.69 & -1.79 & 2.22 & -4.20 \\
\hline
\end{tabular}

Note: This table is similar to Table 7 except this specification measures GPA nonlinearly with indicators for bins of GPA that are .5 GPA points wide. 
Table A7: CDF of GPA

\begin{tabular}{lcccccccc} 
& \multicolumn{8}{c}{ GPA Thresholds } \\
Sample & 0.5 & 1.0 & 1.5 & 2.0 & 2.5 & 3.0 & 3.5 & 4.0 \\
\hline & & & & & & & & \\
1988 & 0.07 & 0.14 & 0.26 & 0.47 & 0.70 & 0.89 & 0.99 & 1.00 \\
2002 & 0.06 & 0.12 & 0.20 & 0.36 & 0.56 & 0.81 & 0.96 & 1.00 \\
\hline
\end{tabular}

Notes: This shows the fraction of students with a GPA below each of the following thresholds separately by 1988 and 2002.1988 refers to NELS:88 and 2002 refers to ELS:2002. 